\title{
Analysis of GPS radio occultation data from the FORMOSAT-3/COSMIC and Metop/GRAS missions at CDAAC
}

\author{
W. Schreiner, S. Sokolovskiy, D. Hunt, C. Rocken, and Y.-H. Kuo \\ University Corporation for Atmospheric Research, 3300 Mitchell Lane, Boulder, USA
}

Received: 11 March 2011 - Published in Atmos. Meas. Tech. Discuss.: 29 April 2011

Revised: 30 August 2011 - Accepted: 15 September 2011 - Published: 20 October 2011

\begin{abstract}
This study investigates the noise level and mission-to-mission stability of Global Positioning System (GPS) radio occultation (RO) neutral atmospheric bending angle data at the UCAR COSMIC Data Analysis and Archive Center (CDAAC). Data are used from two independently developed RO instruments currently flying in orbit on the FORMOSAT-3/COSMIC (F3C) and Metop/GRAS (GNSS Receiver for Atmospheric Sounding) missions. The F3C $50 \mathrm{~Hz}$ RO data are post-processed with a singledifference excess atmospheric phase algorithm, and the Metop/GRAS $50 \mathrm{~Hz}$ closed loop and raw sampling (downsampled from $1000 \mathrm{~Hz}$ to $50 \mathrm{~Hz}$ ) data are processed with a zero-difference algorithm. The standard deviations of the F3C and Metop/GRAS bending angles from climatology between 60 and $80 \mathrm{~km}$ altitude from June-December 2009 are approximately 1.78 and $1.13 \mu \mathrm{rad}$, respectively. The F3C standard deviation reduces significantly to $1.44 \mu \mathrm{rad}$ when single-difference processing uses GPS satellites on the same side of the spacecraft. The higher noise level for F3C bending angles can be explained by additional noise from the reference link phase data that are required with singledifference processing. The F3C and Metop/GRAS mean bending angles differences relative to climatology during the same six month period are statistically significant and have values of -0.05 and $-0.02 \mu \mathrm{rad}$, respectively. A comparison of $\sim 13500$ collocated F3C and Metop/GRAS bending angle profiles over this six month period shows a similar mean difference of $\sim 0.02 \pm 0.02 \mu \mathrm{rad}$ between 30 and $60 \mathrm{~km}$ impact
\end{abstract}

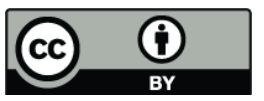

Correspondence to: W. Schreiner (schrein@ucar.edu) heights that is marginally significant. The observed mean difference between the F3C and Metop/GRAS bending angles of $\sim 0.02-0.03 \mu \mathrm{rad}$ is quite small and illustrates the high degree of re-produceability and mission independence of the GPS RO data at high altitudes. Collocated bending angles between two F3C satellites from early in the mission differ on average by up to $0.5 \%$ near the surface due to systematically lower signal-to-noise ratio for one of the satellites. Results from F3C and Metop/GRAS differences in the lower troposphere suggest the Metop/GRAS bending angles are negatively biased compared to $\mathrm{F} 3 \mathrm{C}$ with a maximum of several percents near the surface in tropical regions. This bias is related to different tracking depths (deeper in F3C) and data gaps in Metop/GRAS which make it impossible to process the data from both missions in exactly the same way.

\section{Introduction}

Global Positioning System (GPS) Radio Occultation (RO) data are becoming a benchmark dataset of the international global observing system. The high vertical resolution, precision, and accuracy of retrieved atmospheric profiles make GPS RO ideal for weather (Cucurull et al., 2008; Healy, 2007) and space weather specification and forecasting (Komjathy et al., 2010), climate change research and detection (Leroy, 1997; Steiner et al., 2009), and in-situ, ground-based and satellite instrument validation (Kuo et al., 2004; Ho et al., 2009b). With a GPS receiver on board a low-Earth orbiting (LEO) satellite, the amplitude and phase of the radio frequency (RF) signals transmitted from GPS satellites can be measured very precisely as the ray tangent point descends

Published by Copernicus Publications on behalf of the European Geosciences Union. 


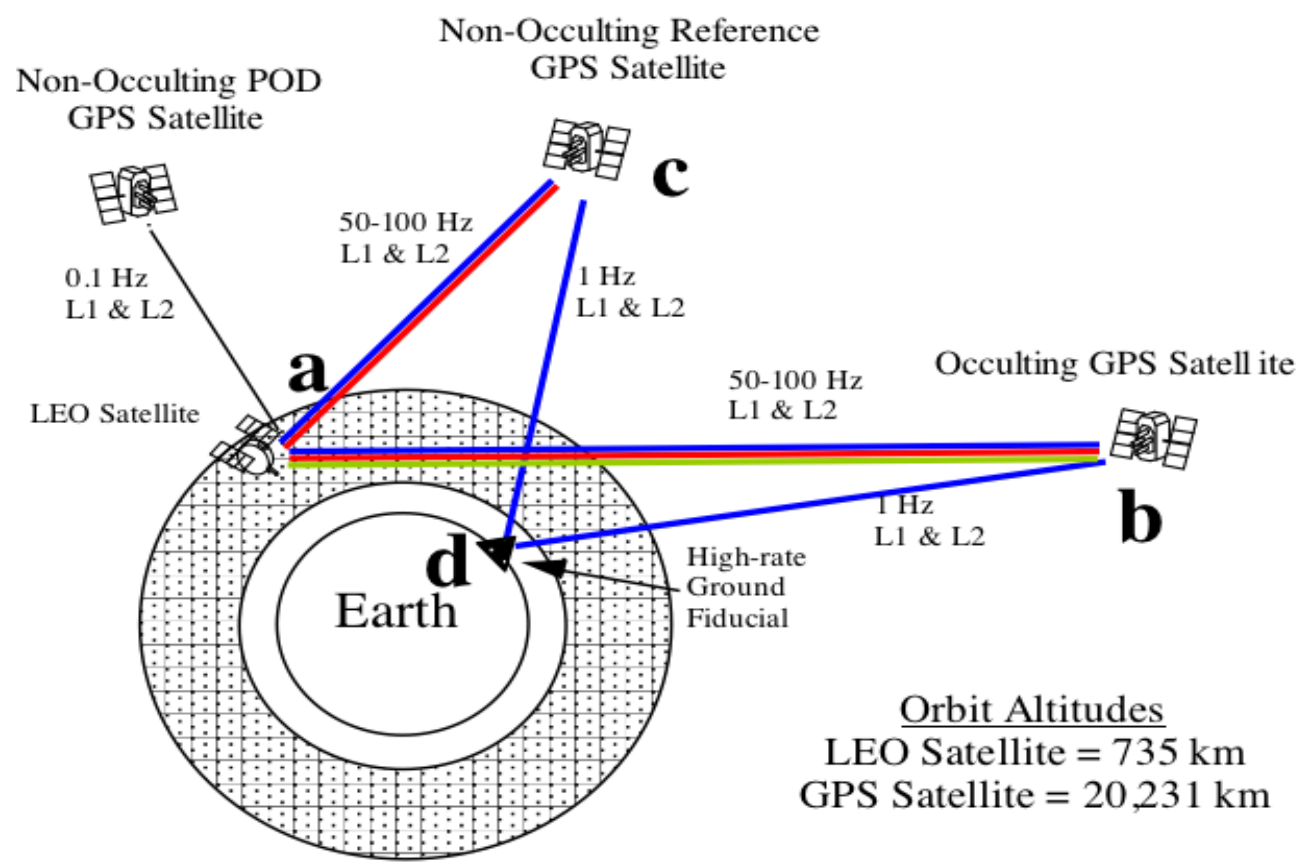

Fig. 1. Diagram of GPS RO observation geometry. Data links used for double differencing are shown in blue. Links for single-differencing are in red. Zero-differencing link shown in green.

from $\sim 100 \mathrm{~km}$ altitude to the surface when the GPS satellite is occulted by Earth's atmosphere. With proper algorithms and observational modeling, we can potentially derive vertical profiles of bending angle (Melbourne et al., 1994; Kursinski et al., 1997; Kuo et al., 2004) that are traceable to the international system of units (SI), i.e. the second (Ohring, 2007). Profiles of refractivity, and subsequently pressure, temperature and humidity can be derived with additional a priori information (Melbourne et al., 1994; Ware et al., 1996; Kursinski et al., 1997; Rocken et al., 1997), but the traceability of these products to SI is diminished.

For GPS RO to be used as a benchmark dataset, especially for climate change research, an important initial step is to establish SI-traceability of the GPS RO bending angle data products through peer-reviewed theoretical and experimental validation studies. The GPS RO phase measurements fundamentally can be traced to the SI second, because the GPS transmitters use on-board atomic clocks that are linked to ground-based atomic clocks with a network of GPS ground fiducial receivers (e.g. National Institute for Standards and Technology (NIST) in Boulder, Colorado) as illustrated in Fig. 1.

The GPS atomic clocks have errors, but they are monitored and corrected with data from the GPS ground network. The LEO clock errors are estimated relative to GPS time along with the LEO satellite positions and velocities within precise orbit determination (POD) data processing to maintain SI traceability (Hwang et al., 2008; Schreiner et al., 2009; Montenbruck et al., 2008; von Engeln et al., 2011). With the raw RO and ground-based GPS measurements and precise positions, velocities, and clocks of GPS and LEO satellites, the fundamental RO observable, the atmospheric excess phase (in excess to vacuum) due to propagation through the atmosphere, can be computed. The atmospheric excess phases for both the L1 and L2 signals during an occultation can be computed accurately using either double-difference, single-difference, or zero (un)-difference processing strategies (Kursinski et al., 1997; Wickert et al., 2002; Hajj et al., 2002; Beyerle et al., 2005; Schreiner et al., 2009).

For altitudes above the moist troposphere where single path propagation allows application of geometric optics (GO), the time derivatives of the L1 and L2 atmospheric excess phases, i.e. excess Dopplers, are noise filtered and used with the positions and velocities of the satellites to compute L1 and L2 bending angles as a function of impact parameter (Kursinski et al., 1997). An ionosphere-free bending angle profile is then traditionally obtained by a linear combination of the L1 and L2 bending angles taken at the same impact parameter (Vorob'ev and Krasil'nikova, 1994). Optimal filtering methods are also used to suppress the larger L2 bending angle noise as described in Sokolovskiy et al. (2009b). In the lower troposphere, where sharp vertical moisture gradients can cause multipath propagation, the $\mathrm{L} 1$ bending angle is derived from the raw phase and amplitude (complex signal) by wave optics (WO) methods (Gorbunov, 2002; Jensen et al., 2003, 2004; Gorbunov and Lauritsen, 2004). Both GO and WO methods use the assumption of local spherical symmetry of refractivity. Finally, the geometric optics and wave optics 
bending angles are combined into one complete ionospherefree bending angle profile.

Many theoretical and experimental validation studies have been published in an attempt to verify the high accuracy (i.e. degree of veracity) and high precision (i.e. degree of reproducibility, between satellites and between instruments) of GPS RO data. The first theoretical estimates of the accuracy of GPS RO in the Earth's neutral atmosphere were published by Yunck and Lindal (1988) and Hardy et al. (1993). A more detailed theoretical analysis of GPS RO accuracy was published by Kursinski et al. (1997). Experimental validation of GPS RO to ancillary data (such as radiosondes or atmospheric model analyses) is a difficult task due to the measurement and representativeness errors of both data sets. The first experimental estimates of the accuracy of GPS RO were obtained by Rocken et al. (1997) by comparing refractivities and temperatures retrieved from GPS/MET data to radiosondes, atmospheric models and other satellite data available at that time. The first experimental estimates of the precision of GPS RO temperatures were obtained by Hajj et al. (2004) by comparing collocated occultations observed by the CHAMP (CHAllenging Minisatellite Payload) and SAC-C (Satélite de Aplicaciones Cientificas - C) satellites, where it was found that individual profiles agree to $0.86 \mathrm{~K}$ i.e. fractionally, to about $0.4 \%$, standard deviation between 5 and $15 \mathrm{~km}$ altitude. The initial deployment phase of the Constellation Observing System for Meteorology Ionosphere and Climate (COSMIC)/Formosa Satellite 3 (FORMOSAT3) (hereafter F3C) RO mission when the six satellites were orbiting very close to each other offered a unique opportunity to estimate the precision of F3C GPS RO refractivities and temperatures by analyzing the differences for collocated occultations (Schreiner et al., 2007; Staten and Reichler, 2009). Recently, structural uncertainties (the differences that depend on tracking depth, noise and processing) of GPS RO refractivity and bending angle in the lower troposphere were explained and quantified by Sokolovskiy et al. (2010). Another important study was recently performed using CHAMP data to quantify the structural uncertainty in CHAMP GPS RO-derived vertical profiles of refractivity and their temporal trends, related to different processing and inversion procedures (Ho et al., 2009a). An experimental validation of bending angles derived from different instruments and processing strategies has also been performed recently by comparing near real-time operational products from the F3C and the Metop/GRAS (GNSS Receiver for Atmospheric Sounding) missions (von Engeln et al., 2011).

In this study we investigate the noise level and consistency of GPS RO bending angle data from the F3C and Metop/GRAS missions. These two missions use independently developed RO instruments: (1) F3C uses an IGOR (Integrated GPS Occultation Receiver) receiver developed at the Jet Propulsion Laboratory (JPL) and (2) Metop-A is flying the GRAS receiver developed by Ruag Space. This study uses six months (June-December 2009) of bending angle data that have been re-processed with consistent software by one data processing center, the UCAR COSMIC Data Analysis and Archive Center (CDAAC). The consistent algorithms and data processing software (to the extent possible with account for differences in the data) used by the CDAAC allow this investigation to quantify bending angle uncertainties due to the instrument only (i.e. minimizes processing software induced structural uncertainty). Therefore, this study quantifies the precision (degree of reproducibility) in terms of random and systematic bending angle differences for different missions/instruments.

Section 1 provides background information and an introduction of this study. Section 2 presents a mission overview and description of the CDAAC data processing used for F3C including POD and computation of atmospheric excess phases and bending angles. Section 3 presents an overview of the Metop/GRAS mission and a description of the CDAAC data processing used for Metop/GRAS including down-sampling the GRAS raw sampled data from $1000 \mathrm{~Hz}$ to $50 \mathrm{~Hz}$ and interpolation through data gaps. Section 4 presents statistical results of RO bending angle comparisons with climatology between 60 and $80 \mathrm{~km}$ altitude for each mission. Section 5 discusses results of an analysis of F3C collocated soundings in close proximity (tangent points within $10 \mathrm{~km}$ ) from the beginning of the mission. Section 6 presents the bending angle differences at large heights observed between collocated F3C and Metop/GRAS profiles that occur within $2 \mathrm{~h}$ and $300 \mathrm{~km}$ of each other. Section $7 \mathrm{in}-$ vestigates differences between $\mathrm{F} 3 \mathrm{C}$ and Metop/GRAS bending angles in the lower troposphere. The last section of the paper presents conclusions of the study.

\section{F3C data processing}

The COSMIC Data Analysis and Archival Center (CDAAC) at UCAR processes the raw F3C RO data into atmospheric profiles in near real time for use by operational weather centers, 2-3 months after real-time with currently developed algorithms and more accurate GPS orbits (i.e. postprocessed solution), and also periodically re-processes all RO missions every 1-2 yr with consistent software to provide the most accurate and stable products for use in climate studies. CDAAC (v3.0) is currently publishing reprocessed data (product version 2010.2640) for F3C as well as other missions including GPS/MET, CHAMP, SAC-C, GRACE, TerraSAR-X, C/NOFS, and Metop/GRAS. The data processing tasks performed at CDAAC that are relevant to this study include: LEO POD and clock estimation, computation of L1 and L2 atmospheric excess phases, and finally calculation of neutral atmospheric bending angles for each LEO occultation event. 


\subsection{F3C IGOR instrument}

The six-satellite $\mathrm{F} 3 \mathrm{C}$ mission is a joint US/Taiwan mission that was successfully launched into orbit at 01:40 UTC on 15 April 2006 (Rocken et al., 2000). The primary instruments are IGOR (Integrated GPS Occultation Receiver) GPS RO receivers developed by the JPL and manufactured by Broad Reach Engineering. The IGOR is an advanced GPS receiver that tracks in both phase-locked loop (PLL) mode and in open-loop (OL) mode; the latter allows tracking of significantly fluctuating RO signals after propagation through the moist lower troposphere without tracking errors and loss of lock (Sokolovskiy, 2001, 2004) and, as the result, reduction of inversion errors and improved penetration of the retrieved profiles to surface (Anthes et al., 2008). Each COSMIC spacecraft utilizes two $1 \times 4$ microstrip patch high-gain limb pointing antennas for $50 \mathrm{~Hz}$ occulting satellite tracking for atmospheric profiling, and two single patch antennas (canted at +15 degree elevation) for $1 \mathrm{~Hz}$ POD (and ionospheric profiling) and $50 \mathrm{~Hz}$ clock reference satellite tracking for atmospheric profiling. The raw RO data output from the IGOR receiver is continuous and consists of receiver time, L1 and L2 pseudorange, carrier phase, and signal-to-noise ratio (SNR) measurements for PLL tracking, and the L1 I\&Q (inphase and quadrature) samples and Doppler and range models for OL tracking.

\subsection{F3C POD processing}

The purpose of the LEO POD process is to accurately determine the position and velocity of the center of mass of the satellite and the clock offset of the GPS receiver that are later used to compute atmospheric excess phases. The CDAAC uses Bernese software (v5.0) to perform the POD of the LEO satellites (Dach et al., 2007). Inputs to this process include the L1 and L2 pseudorange and carrier phase data from a POD antenna, precise IGS (International GNSS Service) Final GPS orbits and transmitter clock offsets from GPS time, LEO attitude information, and earth orientation information. Ionosphere-free phase observations are used in a zero-difference reduced-dynamic filtering approach to estimate the position, velocity, and clock of the LEO as first described by Svehla and Rothacher (2003). Details of the CDAAC POD process are described in Schreiner et al. (2009). Estimation of orbit accuracy for F3C is not possible due to a lack of an alternate measurement system such as a satellite laser ranging retro-reflector. However, the precision of F3C POD has been estimated with external orbit overlap comparisons, i.e. by comparing orbits from different processing centers, and was found to be approximately $17 \mathrm{~cm} \mathrm{3-}$ $\mathrm{D}$ root mean square (rms) for position and $0.17 \mathrm{~mm} \mathrm{~s}^{-1} 3$-D rms for velocity with negligible $\left(<0.03 \mathrm{~mm} \mathrm{~s}^{-1}\right)$ mean differences (Hwang et al., 2008; Schreiner et al., 2009). The F3C orbit errors have predominantly large time scales $(\sim 100 \mathrm{~min}$ orbit) and therefore are nearly constant during a two minute occultation. During an occultation, a constant error in velocity of $0.17 \mathrm{~mm} \mathrm{~s}^{-1}$ will translate into a bending angle bias of approximately $0.05 \mu \mathrm{rad}$ for any given occultation (Schreiner et al., 2009). In general the orbit errors should not translate into a significant systematic bending angle bias when averaging many occultations since the $\mathrm{F} 3 \mathrm{C}$ velocity errors have negligible bias (i.e. $0.03 \mathrm{~mm} \mathrm{~s}^{-1}$ translates into $<0.01 \mu \mathrm{rad}$ ).

\subsection{Atmospheric excess phase processing}

At CDAAC the atmospheric excess phases for each F3C occultation event are computed using the single-difference processing strategy detailed in Schreiner et al. (2009) and illustrated in Fig. 1. Single-difference processing eliminates the LEO clock errors by subtracting the occulting and nonocculting (clock reference) satellite observables and removes the effects of GPS satellite clock errors by applying previously solved-for GPS satellite clock offsets. A recent change to CDAAC (v3.0) for F3C processing results in computing the L2 atmospheric excess phase with an ionosphere-free phase for the reference link L3 based on L1, i.e.

$\mathrm{L} 3_{a}^{c}=\mathrm{L} 1_{a}^{c}+c_{2}\left\langle\mathrm{~L} 1_{a}^{c}-\mathrm{L} 2_{a}^{c}\right\rangle$

where \langle\rangle denotes smoothing with a $2 \mathrm{~s}$ window, $\mathrm{L} 1$ and L2 are the raw phase measurements, $c_{2}=f_{2}^{2} /\left(f_{1}^{2}-f_{2}^{2}\right), f_{1}=$ $1.57542 \mathrm{GHz}$ and $f_{2}=1.2276 \mathrm{GHz}$ constant, and $a$ and $b$ are defined as in Fig. 1. Previously the L2 atmospheric excess phase was computed with an ionosphere-free phase on the reference link L3 based on L2, i.e.

$\mathrm{L} 3_{a}^{c}=\mathrm{L} 2_{a}^{c}+c_{1}\left\langle\mathrm{~L} 1_{a}^{c}-\mathrm{L} 2_{a}^{c}\right\rangle$

where $c_{1}=f_{1}^{2} /\left(f_{1}^{2}-f_{2}^{2}\right)$. This recent processing change results in a reduction of noise for the $\mathrm{F} 3 \mathrm{C}$ L2 atmospheric excess phases that significantly reduces the ionosphere-free bending angle noise observed between 60 and $80 \mathrm{~km}$ by $\sim 6 \%$ (Schreiner et al., 2010).

\subsection{Calculation of bending angles}

The calculation of bending angles performed by the CDAAC software is outlined in Kuo et al. (2004) in part related to the use of PLL data. An initial processing of the OL data, i.e. calculation of the connected excess phase and amplitude from I and Q samples is discussed in detail by Sokolovskiy et al. (2009a).

Initially, calculation of bending angles includes truncation of the L1 signal at the bottom of an occultation. For RO signals acquired in PLL mode, the truncation is based on deviation of the observed excess Doppler from a reference model calculated with GPS and LEO orbits and refractivity climatology (large deviation indicates tracking errors) (Kuo et al., 2004). For RO signals acquired in OL mode, the truncation is based on deviation of smoothed SNR from a background value estimated at the bottom of an occultation (Sokolovskiy et al., 2010). 

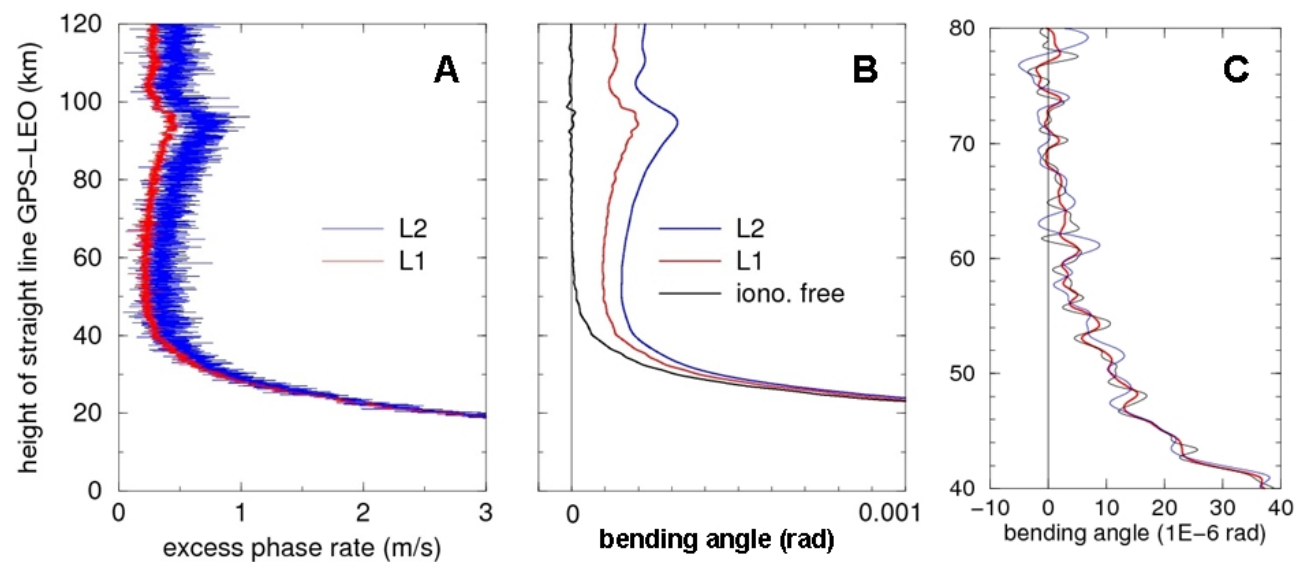

Fig. 2. Panel A: L1 (red) and L2 (blue) excess Dopplers; panel B: L1 (red), L2 (blue) and ionosphere-free L3 (black) bending angles; panel C: ionosphere free bending angles obtained by different smoothing of L4 Doppler (for details see text).

Next, raw excess phases are smoothed with a 3-pass Savitzky-Golay filter (sliding polynomial regression) of third degree and first order (to obtain derivative) and a $0.5 \mathrm{~s}$ window for L1 excess phase. Additionally, both L1 and L2 excess phases are smoothed with a larger window for calculation of ionospheric bending $\alpha_{4}$ (described below in this paragraph). Then, at altitudes above the moist troposphere, the smoothed excess Doppler frequency shift and the satellite positions and velocities are used to solve for the starting and arrival angles of the ray at the GPS and the LEO satellites assuming single path propagation and local spherical symmetry of refractivity (Kursinski et al., 1997). These angles are then used to calculate both the L1 and L2 bending angles and the impact parameters. Finally, the ionosphere-free bending angle $\alpha_{3}$ is calculated as $\alpha_{1}+c_{2} \alpha_{4}$ where $\alpha_{4}=\alpha_{1}-\alpha_{2}$ and all bending angles are taken at the same value of the impact parameter (Vorob'ev and Krasil'nikova, 1994). The larger smoothing window used for calculation of $\alpha_{4}$ is determined individually for each occultation by optimally balancing the un-filtered L2 noise and the un-corrected small-scale ionospheric effects and thus minimizing the residual noise on the ionosphere-free bending angle (Sokolovskiy et al., 2009b). Figure 2a shows L1 and L2 excess Dopplers for F3C occultation and Fig. $2 \mathrm{~b}$ shows the $\alpha_{1}, \alpha_{2}$ and $\alpha_{3}$ bending angles as functions of impact height. It is seen that the ionospheric correction does not completely eliminate the small-scale ionospheric effects. Figure 2c shows zoomed $\alpha_{3}$ profiles calculated with different windows for computation of $\alpha_{4}: 0.5 \mathrm{~s}$ (black), $2 \mathrm{~s}$ (blue), and optimal window $0.75 \mathrm{~s}$ (red) which minimizes the residual noise on $\alpha_{3}$ for this occultation.

In the moist troposphere, the L1 bending angle is derived from the raw (un-smoothed) complex signal (phase and amplitude) using the full spectrum inversion (FSI) method (Jensen et al., 2003). Propagation of the signal from the observational (GPS and LEO) trajectories to closest circles is performed by use of the phase model obtained from
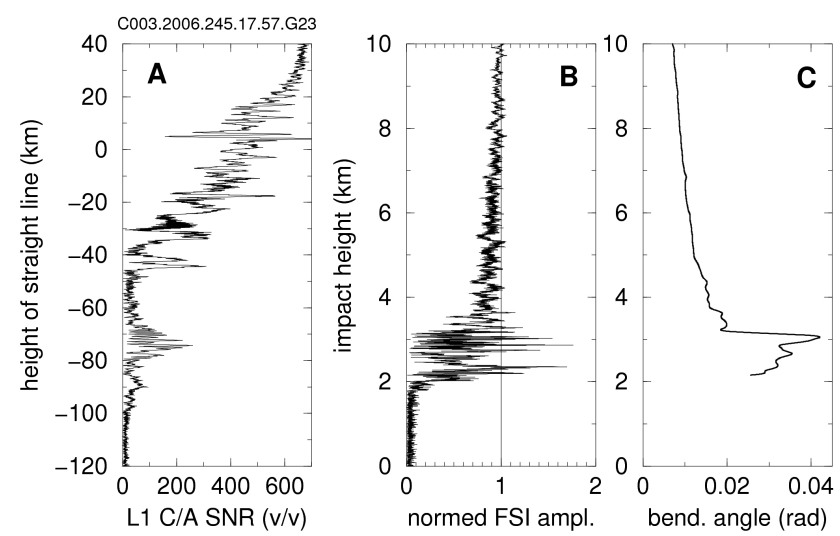

Fig. 3. Panel A: amplitude of raw RO signal (as function of straightline height); panels $\mathbf{B}$ and $\mathbf{C}$ : amplitude and bending angle as functions of impact height derived from the FSI-transformed signal.

smoothed excess phase. Figure 3a shows L1 amplitude (SNR) as function of height of straight line GPS-LEO for a F3C sub-tropical occultation. Figure $3 \mathrm{~b}$ and $\mathrm{c}$ shows amplitude of the FSI-transformed signal and bending angle derived from the phase of that signal, as functions of impact height. The height where the FSI amplitude transitions to noise is used for truncation of the retrieved bending angle profile. For validation of the FSI method, the bending angle in the lower troposphere is derived by the phase matching (PM) method (Jensen et al., 2004). Figure 4a shows a comparison of the bending angle profiles for $\mathrm{F} 3 \mathrm{C}$ tropical occultation derived by FSI and PM, and Fig. 4b and c shows statistical comparison of the bending angles derived for 1 day of F3C data with ECMWF analysis. Fractional difference between the FSI and PM bending angles is less than 0.001 which may be considered negligible compared to other biases of RO in LT.

Finally, WO and GO derived bending angles are connected in one profile at a transition height which is determined 

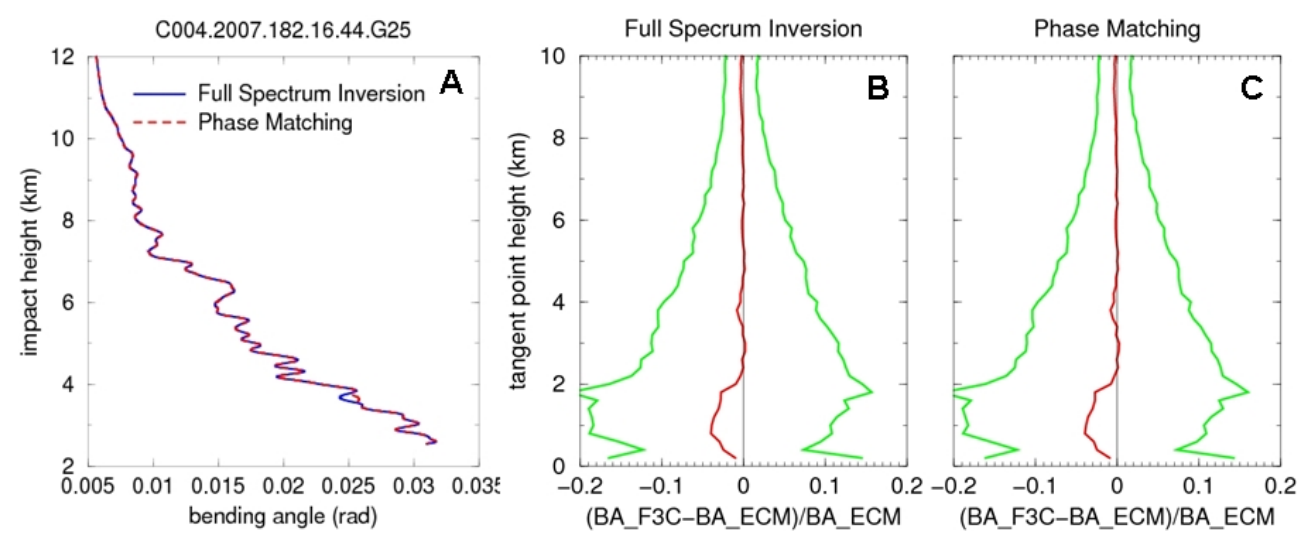

Fig. 4. Panel A: comparison of bending angle profiles derived by FSI and PM for one occultation; panels $\mathbf{B}$ and $\mathbf{C}$ : statistical comparisons of the bending angles derived by FSI and PM to ECMWF-derived bending angles for 1 day (red: mean difference, green \pm standard deviation).

individually for each occultation based on the quality of the L2 signal. Increase in noise on the raw L2 Doppler $(>6 \mathrm{~Hz})$ or mean deviation between smoothed L1 and L2 (scaled by $\left.f_{1} / f_{2}\right)$ Dopplers $(>1 \mathrm{~Hz}$ ), whichever occurs at the higher altitude, are used to determine the transition height. If the transition height appears to be $>20 \mathrm{~km}$ the occultation is discarded. Above the transition height the GO bending angle is corrected for the ionosphere effects as discussed above, and below the WO bending angle is corrected by constant $\alpha_{4}$ averaged over $3 \mathrm{~s}$ of data above the transition height.

\section{Metop/GRAS data processing}

\subsection{Metop/GRAS instrument}

The Metop/GRAS mission is a joint EUMETSAT (European Organization for the Exploitation of Meteorological Satellites) and ESA (European Space Agency) RO mission that was successfully launched into orbit on Metop-A in October 2006. The GRAS instrument consists of an advanced GPS RO receiver, two independent L1 and L2 zenith facing (GZA) POD antennas, and fore and aft high-gain 18-patch occultation (GVA) antennas (Montenbruck et al., 2008). The GRAS receiver tracks GPS satellite signals at $50 \mathrm{~Hz}$ in phaselocked loop mode and at $1000 \mathrm{~Hz}$ in a raw-sampling mode that is similar but not identical to IGOR OL tracking. While the IGOR receiver uses both frequency and range models without feedback from RO signal, the GRAS receiver uses a frequency model without feedback (with $1000 \mathrm{~Hz}$ sampling, this model does not have to be as accurate as in IGOR) and a delay-locked loop (DLL). When the GRAS receiver maintains lock on the C/A code, this, generally, results in higher SNR than with the use of a model without feedback. However, due to strong variations of SNR in the moist lower troposphere, the DLL often loses lock which generates data gaps and results, on average, in lower tracking depth than IGOR receiver (this will be further discussed in Sect. 7).
While the IGOR receivers output phase and amplitude time tagged in GPS seconds the GRAS instrument produces much lower level observations, namely, noise and gain histograms, temperatures, voltages, I and Q with reference model and time tags in oscillator ticks. With information from GRAS receiver documentation (e.g. the GRAS Measurement Data Interpretation and Description (MDID) document) and assistance from EUMETSAT, UCAR developed a CDAAC level 0 to level 1a Perl software module that converts GRAS raw packets into $1 \mathrm{~Hz}, 50 \mathrm{~Hz}$ and $1000 \mathrm{~Hz}$ phase and amplitude data. The GRAS phase and amplitude data produced by CDAAC shows good agreement with data generated with the EUMETSAT "PyGRAS" software.

\subsection{Metop/GRAS POD processing}

The CDAAC used Bernese software (v5.0) to perform precise orbit determination (POD) for the Metop-A satellite. Inputs to this process included the Metop/GRAS L1 and L2 pseudorange and carrier phase data from the GZA antenna, IGS Final GPS orbits, 30-s IGS-provided transmitter clock offsets from GPS time and Earth orientation information, Metop-A attitude information and GZA antenna offset and L1 and L2 antenna phase center variations. Ionospherefree phase observations were used in a zero-difference dynamic filtering approach to estimate the position, velocity, and clock of the LEO.The POD was computed over a $27 \mathrm{~h}$ data arcs using 30-s carrier phase observations from the GZA antenna. The state vector estimated in this processing consists of 6 osculating elements (position and velocity), 9 radiation pressure acceleration terms (bias and 1 cycle-perorbit-revolution in radial, transverse, and normal directions), stochastic velocity pulses every $6 \mathrm{~min}$, real valued ambiguities for each tracking arc, and the precise LEO clock offset at the $30 \mathrm{~s}$ epochs. Additional perturbing accelerations modeled in the equations of motion include the EIGEN1S earth gravity model used to degree/order 140, third body tidal accelerations due to the sun and moon, indirect tidal 


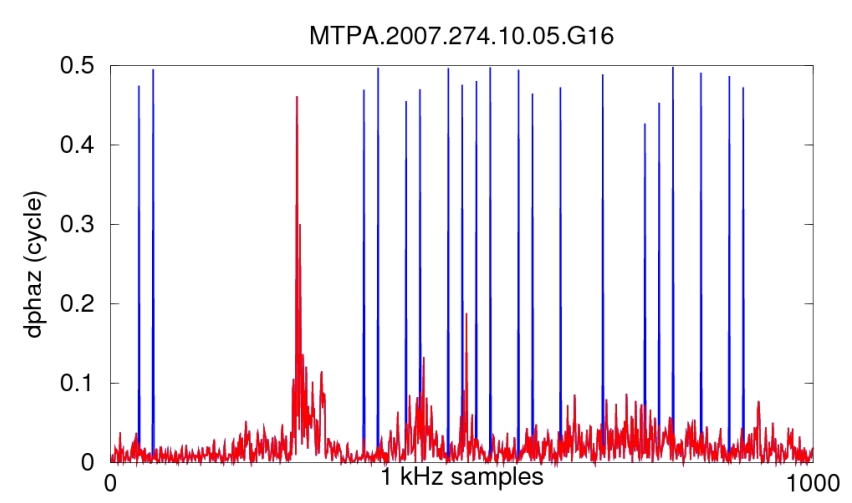

Fig. 5. Phasor rotation (between adjacent $1000 \mathrm{~Hz}$ samples) of Gras/METOP raw sampled RO signal down-converted with the frequency model based on refractivity climatology. Blue line corresponds to original signal $(50 \mathrm{~Hz}$ navigation data modulation phase jumps are well seen); red line corresponds to the signal after removal of the $50 \mathrm{~Hz}$ modulation.

accelerations due to solid earth and ocean tides, and general relativistic effects.

Table 1 presents a summary of Metop/GRAS POD precision obtained from a one month (2007.274-304) external orbit overlap comparison between UCAR/CDAAC and EUMETSAT. The average 3-D rms velocity difference between the CDAAC and EUMETSAT orbits is $0.08 \mathrm{~mm} \mathrm{~s}^{-1}$ for the one month period. This is slightly worse but consistent with previous Metop/GRAS inter-agency orbit comparisons presented by Montenbruck et al. (2008). These results suggest that the Metop/GRAS POD quality at CDAAC is better than that of $\mathrm{F} 3 \mathrm{C}$ in terms of rms. The mean differences are insignificant at a level of $\sim 0.01 \mathrm{~mm} \mathrm{~s}^{-1}$ and should not translate into significant systematic bending angle biases when averaging many occultations.

\subsection{Atmospheric excess phase processing}

The CDAAC atmospheric excess phase data for Metop/GRAS are generated with a zero-difference processing approach (Beyerle et al., 2005). This method of processing is possible due to an ultra-stable $28.25 \mathrm{MHz}$ oscillator that produces an almost linear receiver clock offset in time (Montenbruck et al., 2008). Instead of having to eliminate the LEO clock errors from the occulting satellite data by subtracting reference satellite data as done in single-differencing, they can be removed with a low degree polynomial fit to the $30 \mathrm{~s}$ LEO clock offsets estimated in the POD solution. The CDAAC software applies a quadratic fit to the LEO POD clock offsets over a 5 min duration. The GPS satellite clock errors are removed from the occulting link data by interpolating the 30 s IGS Final clock offset estimates as is performed in single-difference processing. To complete computation of the atmospheric excess phases, all remaining effects are modeled and removed from the raw occulting link data as described in Schreiner et al. (2009).

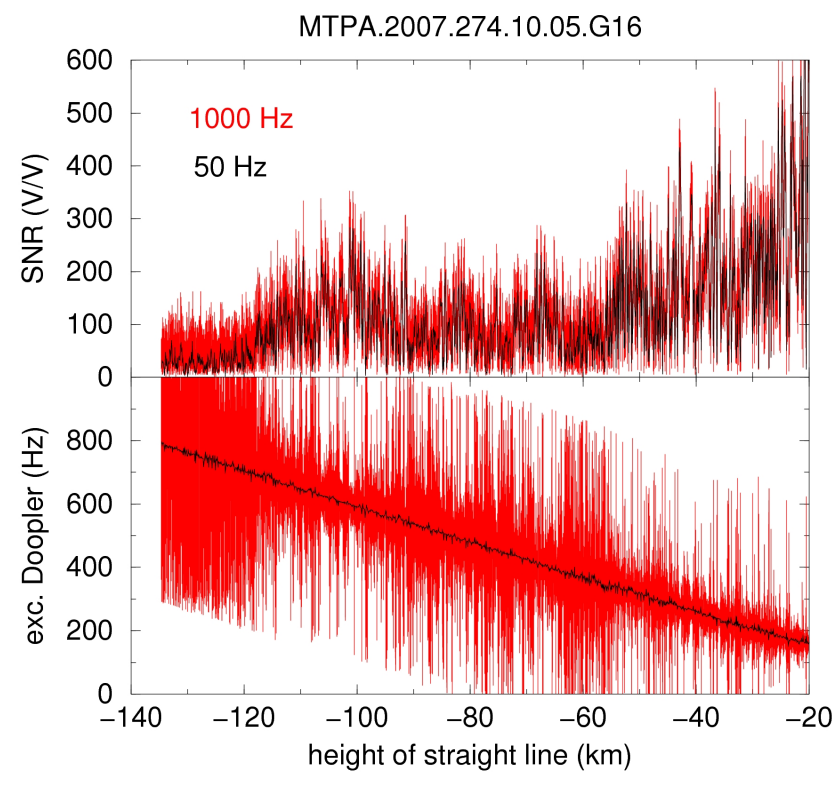

Fig. 6. Amplitude (upper panel) and Excess Doppler (lower panel) of Metop/GRAS raw sampled signal at $1000 \mathrm{~Hz}$ (red line) and down-sampled to $50 \mathrm{~Hz}$ (black line).

Zero-difference atmospheric excess phase data have less noise than single-difference excess phases, because the noise from the reference link data is not introduced into the processing. Zero-difference processing was first demonstrated with data from the GRACE-A RO mission and resulted in refractivity profiles of superior quality to single-difference profiles using a traditional ionospheric calibration of the reference link data, and profiles of similar quality when using a modified ionospheric correction to reduce L2 reference link noise (Beyerle et al., 2005). Section 4 shows that CDAAC zero-difference atmospheric excess phases for Metop/GRAS have improved noise performance over singledifference excess phases.

\subsection{Down-sampling $1000 \mathrm{~Hz}$ raw sampled data to $50 \mathrm{~Hz}$}

CDAAC inversion software is set to process $50 \mathrm{~Hz}$ sampled RO signals. Thus the Metop/GRAS raw $1000 \mathrm{~Hz}$ data are down-sampled to $50 \mathrm{~Hz}$ prior to inversion.

At first, the raw $1000 \mathrm{~Hz}$ sampled complex signal is downconverted (frequency-shifted to zero) by use of the reference phase model calculated from GPS and LEO orbits and refractivity climatology. Figure 5 (blue line) shows the phasor rotation (in cycles) between adjacent $1000 \mathrm{~Hz}$ samples after the down-conversion. The navigation data modulation phase flips are well seen because of high enough SNR and can be removed by 2-quadrant phase extraction for these data, but this can not be reliably done for lower SNR. At CDAAC, the navigation data modulation for Metop/GRAS data is removed by aligning the RO signal with the navigation data bit sequence received on the ground with account for GPS time 
Table 1. Summary of Metop/GRAS external orbit overlap comparison between UCAR and EUMETSAT for 2007.274-305.

\begin{tabular}{|c|c|c|c|c|}
\hline & $\begin{array}{r}\text { Radial } \\
\text { POS }[\mathrm{cm}] \\
\left(\text { VEL: }\left[\mathrm{mm} \mathrm{s}^{-1}\right] \text { ) }\right.\end{array}$ & $\begin{array}{r}\text { Along-Track } \\
\text { POS [cm] } \\
\text { (VEL: }\left[\mathrm{mm} \mathrm{s}^{-1}\right] \text { ) }\end{array}$ & $\begin{array}{r}\text { Cross-Track } \\
\text { POS [cm] } \\
\left(\text { VEL: }\left[\mathrm{mm} \mathrm{s}^{-1}\right] \text { ) }\right.\end{array}$ & $\begin{array}{r}\text { 3-D Root Sum Square } \\
\text { POS }[\mathrm{cm}] \\
\left.\text { (VEL: }\left[\mathrm{mm} \mathrm{s}^{-1}\right]\right)\end{array}$ \\
\hline Mean & $0.7(-0.01)$ & $0.9(-0.01)$ & $2.9(0.00)$ & - \\
\hline STD & $4.2(0.05)$ & $6.0(0.08)$ & $4.1(0.04)$ & $8.6(0.08)$ \\
\hline
\end{tabular}

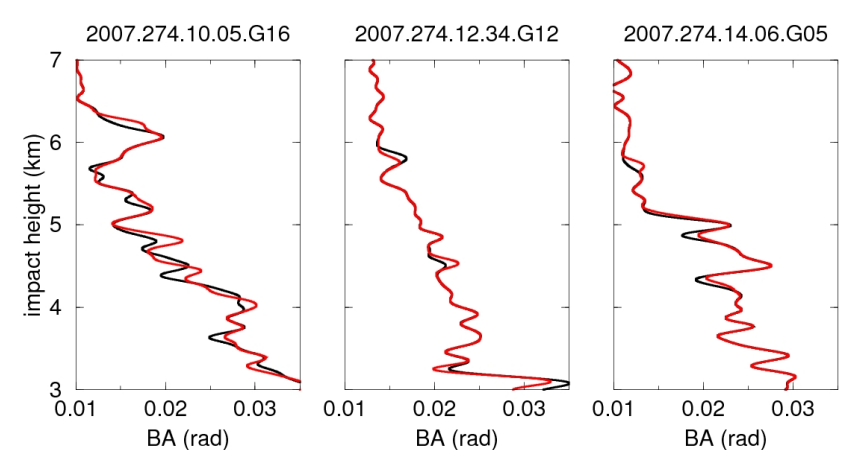

Fig. 7. L1 bending angles retrieved from Metop/GRAS raw sampling data for three tropical occultations by phase matching. Red and black lines correspond to retrieval from $1000 \mathrm{~Hz}$ samples and from $50 \mathrm{~Hz}$ samples (after down-sampling).

tags and propagation time between GPS and LEO. Figure 5 (red line) shows the phasor rotation after removal of the navigation data modulation. The down-sampling is performed by averaging every 20 samples of I and Q of the down-converted $\mathrm{RO}$ signal. If the down-sampling is performed after removal of the navigation data modulation, the shift of the averaging intervals in time does not matter, otherwise these intervals must be aligned with the $20 \mathrm{~ms}$ navigation data chips. The $20 \mathrm{~ms}$ averaged I and Q represent the raw $50 \mathrm{~Hz}$ downsampled RO signal. They are used for calculation of the amplitude and phase by 4-quadrant phase extraction, connection of the phase (Sokolovskiy, 2009a), and calculation of the excess phase by up-conversion with the phase model. Figure 6 shows amplitude (upper panel) and excess Doppler (lower panel) calculated from raw $1000 \mathrm{~Hz}$ sampled signal (red) and down-sampled to $50 \mathrm{~Hz}$ (black). It is seen that the down-sampling, which includes low-pass filtering (integration), substantially reduces fluctuation of the RO signal, especially of Doppler.

In previous studies, based on simulations, it was found that $50 \mathrm{~Hz}$ sampling rate is sufficient to capture the spectral content of RO signals in most cases (not accounting for reflected signals) and $100 \mathrm{~Hz}$ may be needed in extreme cases (Sokolovskiy, 2001) but experimental verification was addressed in the future. The $1000 \mathrm{~Hz}$ sampled data allow such verification, which we perform here based on analysis of individual occultations. We select several Metop/GRAS

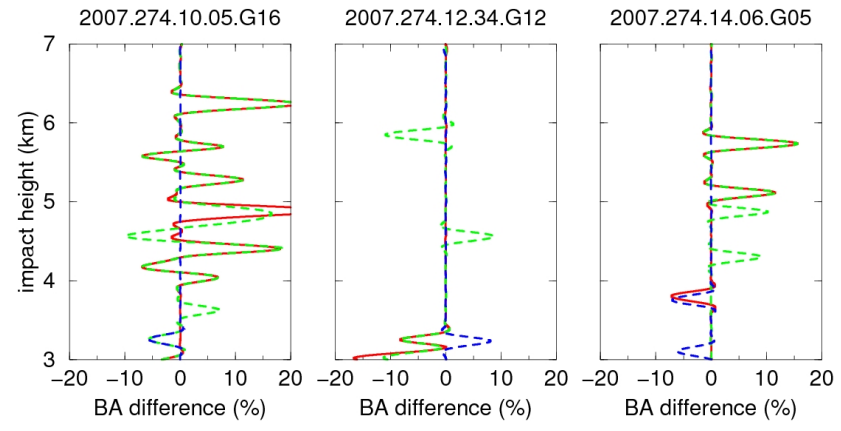

Fig. 8. Differences of the bending angles from those retrieved from $50 \mathrm{~Hz}$ down-sampled signals (as discussed in Sect. 3.4) for three tropical occultations. Red, green and blue lines corresponds to down-sampling to $100 \mathrm{~Hz}$, the use of raw $1000 \mathrm{~Hz}$ samples and down-sampling to $50 \mathrm{~Hz}$ with Gaussian filter, respectively.

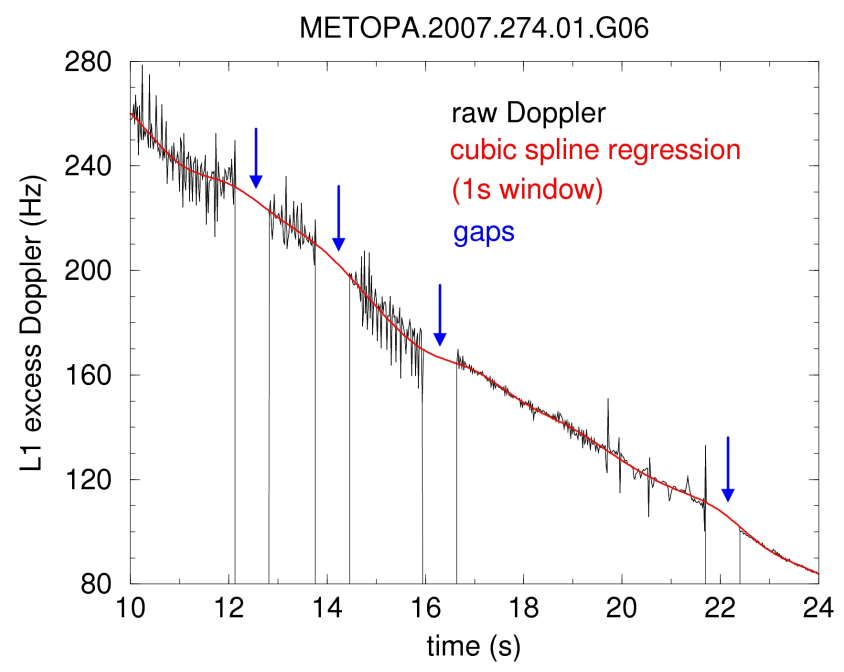

Fig. 9. Filling gaps in Metop/GRAS PLL Doppler data with cubic spline regression.

tropical occultations (with longest extension of raw sampling and without data gaps) and calculate bending angles by PM method for $1000 \mathrm{~Hz}$ and down-sampled RO signals. Figure 7 shows three bending angle profiles retrieved from Metop/GRAS RO raw signals sampled at $1000 \mathrm{~Hz}$ (red lines) and down-sampled to $50 \mathrm{~Hz}$ (black lines). Figure 8 shows the 


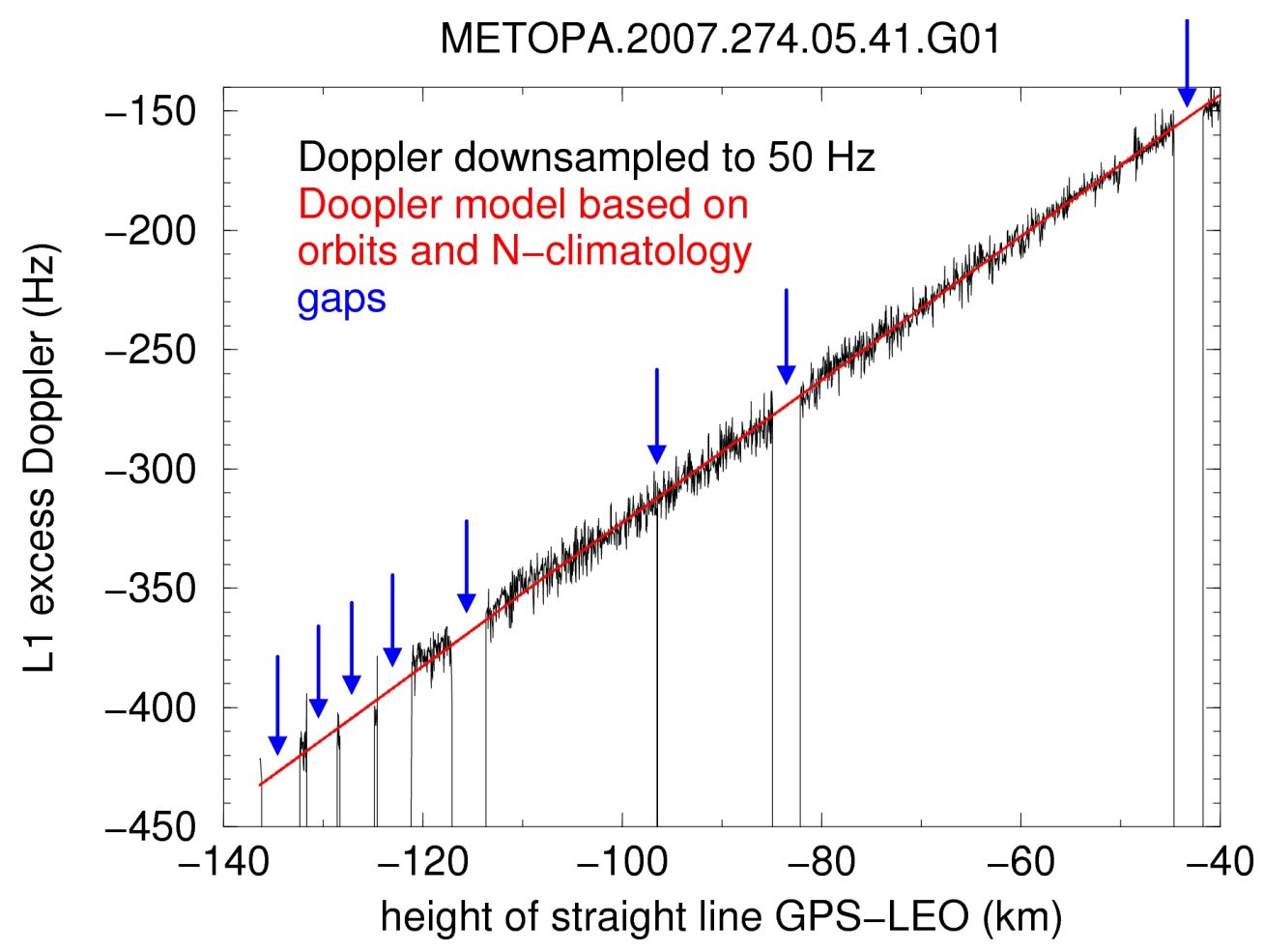

Fig. 10. Filling gaps in Metop/GRAS raw-sampled Doppler data with the model based on refractivity climatology.

bending angles profiles differenced with the profile obtained by down-sampling to $50 \mathrm{~Hz}$ (used here as the reference) for the same occultations as in Fig. 7. Red lines correspond to down-sampling to $100 \mathrm{~Hz}$ (with $10 \mathrm{~ms}$ integration interval); green lines correspond to the original $1000 \mathrm{~Hz}$ sampled signal; blue lines correspond to down-sampling to $50 \mathrm{~Hz}$ with integration in $60 \mathrm{~ms}$ window with Gaussian weighting function of $20 \mathrm{~ms}$ width. For the first occultation (left panel), the difference between the $1000 \mathrm{~Hz}$ and $100 \mathrm{~Hz}$ samplings is smaller than between any of them and $50 \mathrm{~Hz}$ sampling, suggesting that $50 \mathrm{~Hz}$ sampling may not capture full spectral content of the RO signal, which is captured by both 100 and $1000 \mathrm{~Hz}$ samplings. For the second occultation (middle panel) the difference between $50 \mathrm{~Hz}$ and $100 \mathrm{~Hz}$ samplings is smaller than between any of them and $1000 \mathrm{~Hz}$ sampling, suggesting that $50 \mathrm{~Hz}$ sampling is sufficient and the latter difference is related to the noise in $1000 \mathrm{~Hz}$ signal, filtered in the process of down-sampling. The third occultation (right panel) suggests that the effects of under-sampling with $50 \mathrm{~Hz}$ and noise in $1000 \mathrm{~Hz}$ signal are both present. These results suggest the use of $100 \mathrm{~Hz}$ sampling in the LT in future RO receivers. The small difference between simple integration (frequency response function has side-lobes) and more optimal integration with Gaussian weighting function (no sidelobes) suggests that the simple integration currently applied for the GPS RO signal noise filtering is sufficient.

\subsection{Interpolation through data gaps}

Contrary to F3C occultations, the Metop/GRAS occultations contain time intervals with missing data (data gaps), which occur mainly in the troposphere both in PLL and OL modes (according to our analysis, for October 2007, $60 \%$ of occultations have data gaps in PLL and/or OL modes). The presence of data gaps offers a choice of either processing contiguous parts of occultations down to the first gap (this may result in poor penetration of retrieved bending angle profiles) or interpolating data through gaps (this makes the retrieved bending angles dependent on the interpolation strategy, especially if the total length of data gaps for a given occultation is large), or processing occultations with gaps without interpolation. The latter option is possible in GO by calculating a piecewise bending angle profile (will be affected by end-effects of the filtering) and in WO by applying methods that do not use fast Fourier transform (FFT), such as PM. The use of FFT requires uniformly sampled signal, i.e. interpolation through gaps. On the other side, application of PM to the signal with gaps is equivalent to setting amplitude inside the gaps to zero (then the phase filled in the gaps does not contribute) and applying an FFT based WO method, such as FSI, CT (Gorbunov, 2002) or CT2 (Gorbunov and Lauritsen, 2004). The effect of data gaps with amplitude set to zero on WO inversions is demonstrated below. 

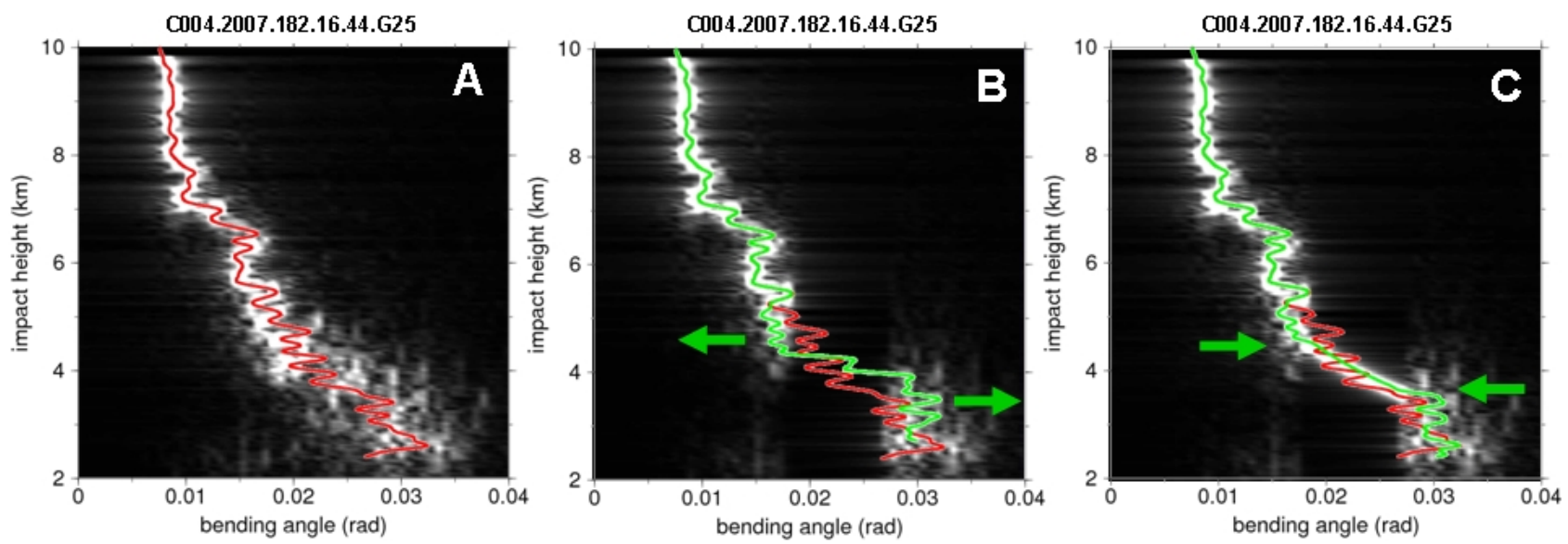

Fig. 11. Sliding spectrograms of F3C RO signals transformed to impact parameter representation (gray scale) and retrieved bending angle profiles (color lines) for F3C tropical occultation. Red and green lines correspond to bending angle retrieved from original signal and with artificially introduced gap. For details see text.
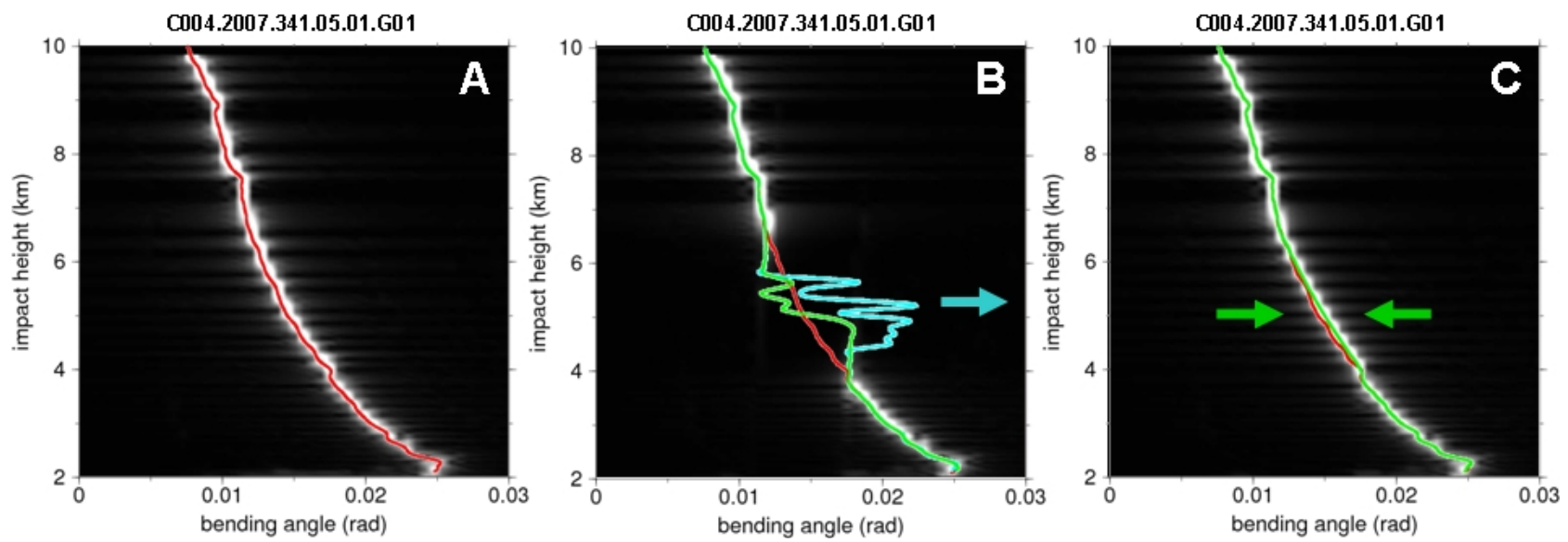

Fig. 12. Same as Fig. 11 but for high-latitude occultation. Green and blue lines in panel $\mathbf{B}$ correspond to the use of RO signal down to $-80 \mathrm{~km}$ and $-150 \mathrm{~km}$ straight-line height.

Interpolation of the excess Doppler through gaps in PLL data is performed by least squares fit of cubic splines (spline regression) defined on $1 \mathrm{~s}$ grid. This is shown in Fig. 9. Interpolation of excess Doppler through gaps in OL data (which, generally, is more noisy than PLL data) is performed with the reference model calculated from GPS and LEO orbits and refractivity climatology (Kirchengast et al., 1999). This is shown in Fig. 10. After filling gaps with Doppler, the accumulated phase is calculated for the whole occultation. For calculation of bending angles by GO, interpolation of the phase through gaps is sufficient because the amplitude is not used. For WO methods, the amplitude has to be interpolated. This is done by a constant value averaged from $0.5 \mathrm{~s}$ of data on one or both sides of the gap.

In order to model the effect of data gaps on the calculation of bending angles we use $\mathrm{F} 3 \mathrm{C}$ occultation data, introduce an artificial gap and compare bending angles retrieved with and without the gap. In GO processing the bending angle, which is locally related to Doppler, simply follows the Doppler filled in the gap. In WO processing, the effect of a gap on bending angle is more complicated; besides the filled Doppler, it depends on the width of the local spectrum of WO transformed signal outside the gap, and on the filled amplitude. Figure 11a-c shows sliding spectrograms in the coordinates (bending angle - impact height) of the WO transformed F3C signal in tropics (broad local spectrum due to moist convection). Red lines show the bending angle calculated from the full signal and green lines from the signal with the artificially introduced gap. Figure 11a correspond to the original signal and Fig. 11b, c to the signals with the gap filled with Doppler model by setting amplitude to zero (Fig. 11b) and by interpolating from the sides of the gap as discussed above (Fig. 11c). When the amplitude inside the gap is set to zero, the filled Doppler has no weight, and the bending angle is 


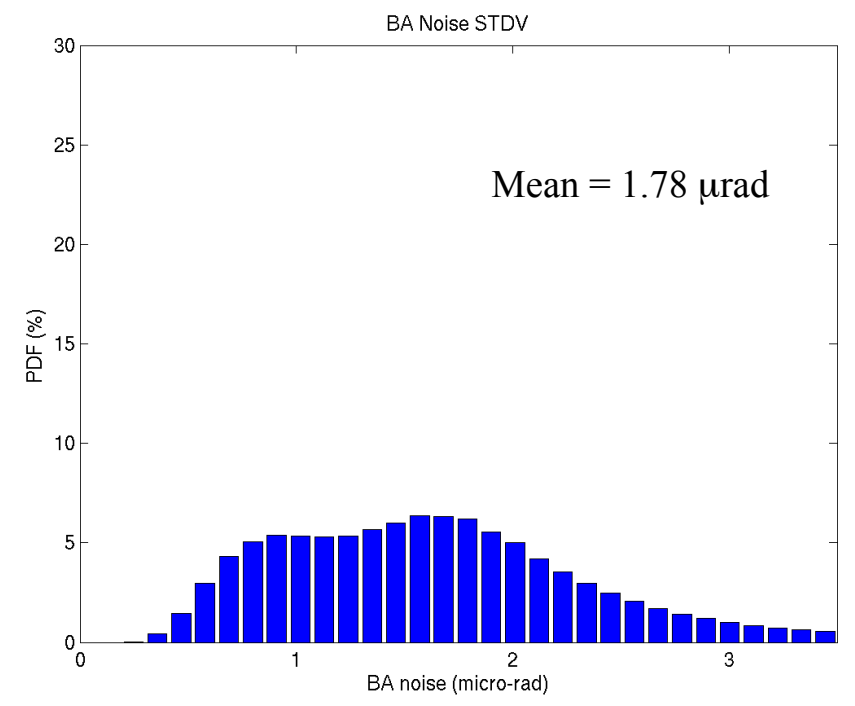

Fig. 13. Distribution of standard deviation of bending angle noise for each occultation between 60 and $80 \mathrm{~km}$ heights for $\sim 308000$ F3C profiles from July-December 2009.

only affected by the spectral density of the original signal (mapping of the spectral content of RO signal from time to impact height representations is discussed in Sokolovskiy et al., 2010) as shown in Fig. 11b. It is seen that that spectral density pulls the retrieved bending angle to negative and positive directions at the upper and lower parts of the impact height interval affected by the gap. This effect is substantially reduced when assigning mean amplitude to the signal filled in the gap (Fig. 11c). We note however, that in some cases, when the true bending angle differs significantly from the climate model (i.e. sharp top of the atmospheric boundary layer) and depending on location and size of the gap, the zero amplitude filling may result in smaller bending angle errors. Figure 12a-c shows sliding spectrograms and bending angle profiles for a high latitude $\mathrm{F} 3 \mathrm{C}$ occultation. It is interesting, that in this case the bias in bending angle, when the amplitude inside the gap is set to zero, is much stronger than for tropical occultation. This is because the spread spectrum of WO transformed signal in the presence of moist convection has enough power to stabilize the bending angle in the presence of the gap (of not too large size), by not allowing deviations larger than the local spectral half-width. This is different for narrow-banded WO transformed signal when even weak spectral density (but located far away from the mean frequency) can substantially bias the retrieved bending angle in the presence of gap filled with zero amplitude. This is seen in Fig. 12b where the use of the RO signal down to low height of straight line (see figure caption) introduces additional weak spectral density of the transformed signal at large frequencies (bending angles) and results in significant positive bias of the bending angle retrieved in the region affected by gap. In this case, assigning mean amplitude

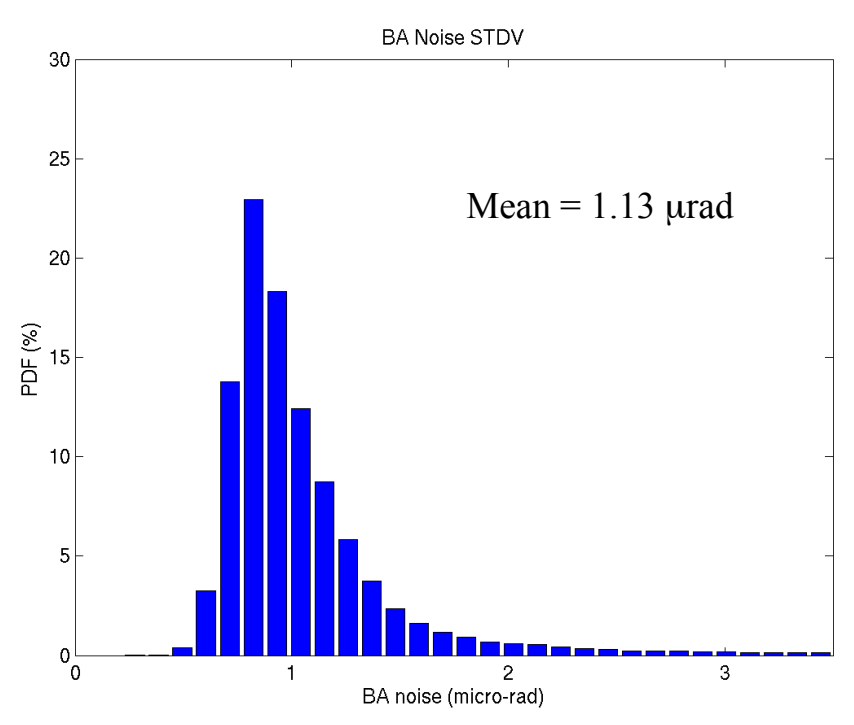

Fig. 14. Distribution of standard deviation of bending angle noise for each occultation between 60 and $80 \mathrm{~km}$ heights for $\sim 79000$ Metop/GRAS profiles from July-December 2009.

to the signal filled in the gap results in that the bending angle basically follows retrieval from the filled Doppler in GO approximation (Fig. 12c).

\section{Comparison of RO bending angles with climatology}

This section examines neutral atmospheric bending angle differences with climatology between 60 and $80 \mathrm{~km}$ heights. During the CDAAC inversion process, the observational bending angle profile is differenced with a climatological (from NCAR climate model) bending angle profile (i.e. RO bending minus climate bending). The mean (SMEAN) and standard deviation (STDV) of these bending angle differences between 60 and $80 \mathrm{~km}$ altitude (a $20 \mathrm{~km}$ interval with minimal neutral atmospheric bending angle, not significantly affected by ionospheric residuals from E layer) are used to estimate errors for quality control purposes. Both SMEAN and STDV also depend on data smoothing (filtering) used in the bending angle calculation. STDV provides a good estimate of the random bending angle noise for a given occultation and is a function of the time derivative of excess phase measurement noise, high-frequency transmitter/receiver clock errors, and small-scale ionospheric residual errors. SMEAN is a function of systematic errors due to transmitter/receiver velocity and clock mismodeling, large-scale ionospheric residual errors, and bending angle climatology.

We examine six months (June-December 2009) of bending angle data from F3C and Metop/GRAS that have been processed with consistent software (version 2010.2640). All F3C and Metop/GRAS profile data used in this study were subjected to the same CDAAC quality control procedures 


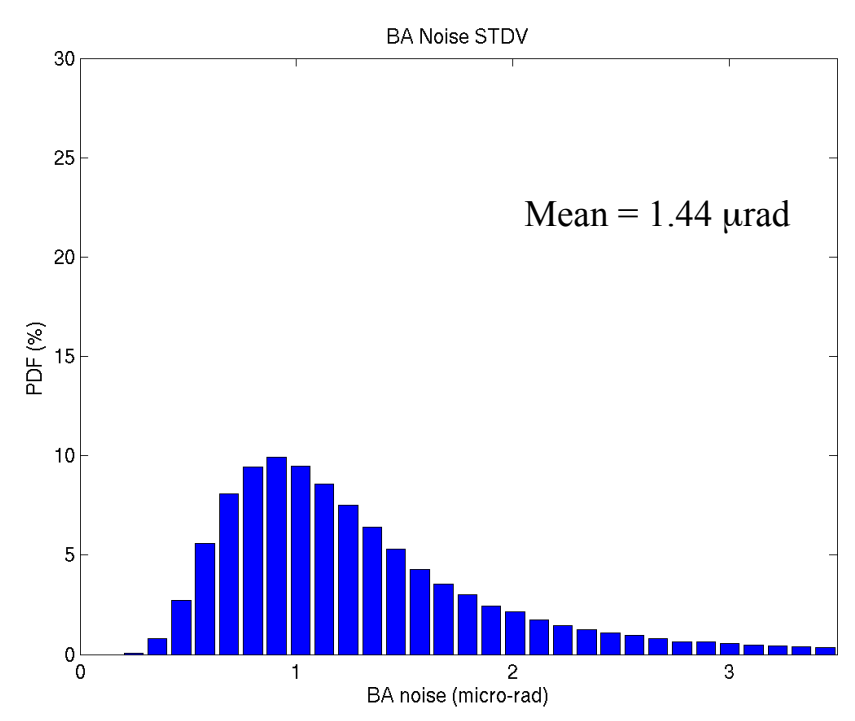

Fig. 15. Distribution of standard deviation of bending angle noise for $\sim 162000 \mathrm{~F} 3 \mathrm{C}$ profiles that used clock reference satellite data acquired on the same side of the F3C satellite as the occulting satellite data.

(Ho et al., 2009a). For this six-month period, F3C and Metop/GRAS receivers tracked approximately 455000 and 102000 occultations. Figures 13 and 14 show histograms of STDV for F3C and Metop/GRAS. The F3C histogram has an interesting bimodal structure with two local maxima at $\sim 0.9$ and $\sim 1.6 \mu \mathrm{rad}$ while Metop/GRAS histogram is unimodal with one clear maximum at $\sim 0.8 \mu \mathrm{rad}$. Since the mean STDV is significantly affected by the "tails" of distributions (this effect is stronger for Metop/GRAS), we remove the profiles with STDV $>10 \mu \mathrm{rad}$ by considering them outliers. This results in the mean STDV of $1.78 \mu \mathrm{rad}$ for F3C (68\% processed occultations) and substantially lower mean STDV of $1.13 \mu \mathrm{rad}$ for Metop/GRAS (77\% processed occultations).

The bimodal distribution for F3C shown if Fig. 13 is unexpected and requires explanation. It arises from two different instances of single-difference processing: (1) using reference and occulting GPS satellite data from the same side of the F3C satellite, i.e. both GPS in fore direction or both in aft direction and (2) using reference and occulting GPS satellite data from the opposite side of the F3C satellite, i.e. one GPS in fore direction and one GPS aft. To illustrate this Fig. 15 shows a histogram of STDV for $\sim 162000$ F3C "same-side" profiles, which has a unimodal distribution and a much lower mean of $1.44 \mu \mathrm{rad}$. Figure 16 shows the results for $\sim 146000$ F3C "opposite-side" occultations and again has a unimodal distribution with a larger mean of $2.16 \mu \mathrm{rad}$. The cause of this significant difference between "same-side" and "oppositeside" single-difference occultations is presently unknown. There appears to be a source of phase noise which is more correlated for antennas on the same side of the satellite and less correlated for opposite sides. One possible cause of this

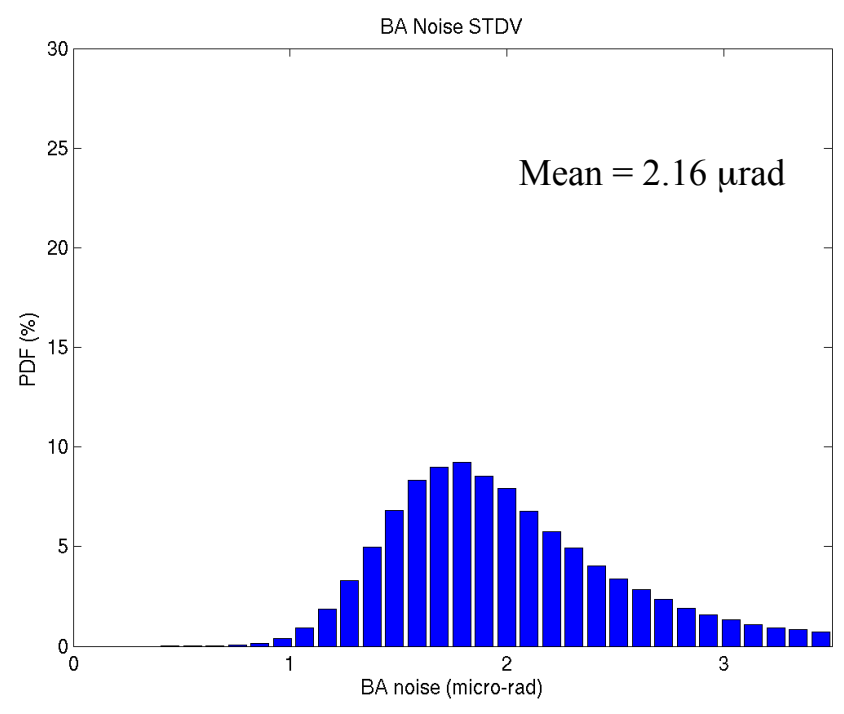

Fig. 16. Distribution of standard deviation of bending angle noise for $\sim 146000$ F3C profiles that used clock reference satellite data acquired on the opposite side of the F3C satellite as the occulting satellite data.

issue is RF interference on the satellite. This issue is currently under investigation. One current opportunity to remedy this problem for future re-processed data is to use only "same-side" single-difference occultations, but this will decrease the total number of successfully processed occultations due to occasionally unusable data from one of the POD antennas on some F3C satellites.

These results re-iterate the improved noise performance that Metop/GRAS bending angles exhibit over F3C as previously shown by von Engeln et al. (2011). The Metop/GRAS bending angles have lower noise predominantly due to zerodifference processing of atmospheric excess phases that is not contaminated with phase errors from reference link data. This claim is supported by results (not shown) for $\sim 16500$ Metop/GRAS single-difference profiles from October 2007 that show a similar STDV distribution and mean $(1.30 \mu \mathrm{rad})$ as seen for the F3C "same-side" single-difference occultations in Fig. 15. Additional factors that may also contribute to lower Metop/GRAS noise are limited local solar time sampling (Metop/GRAS orbit is sun-synchronous at 09:30 LST) that may observe fewer small-scale ionospheric irregularities, and improved L2 semi-codeless tracking algorithms for Metop/GRAS over F3C as shown in Montenbruck et al. (2008).

Next we examine the F3C and Metop/GRAS mean bending angle differences between 60 and $80 \mathrm{~km}$ altitude for the same six-month period (June-December 2009). SMEAN can be a good indicator of large bending angle bias errors, but since it is measured relative to bending angle climatology, smaller magnitudes do not necessarily equate to more accurate profiles. However, since we are investigating the 


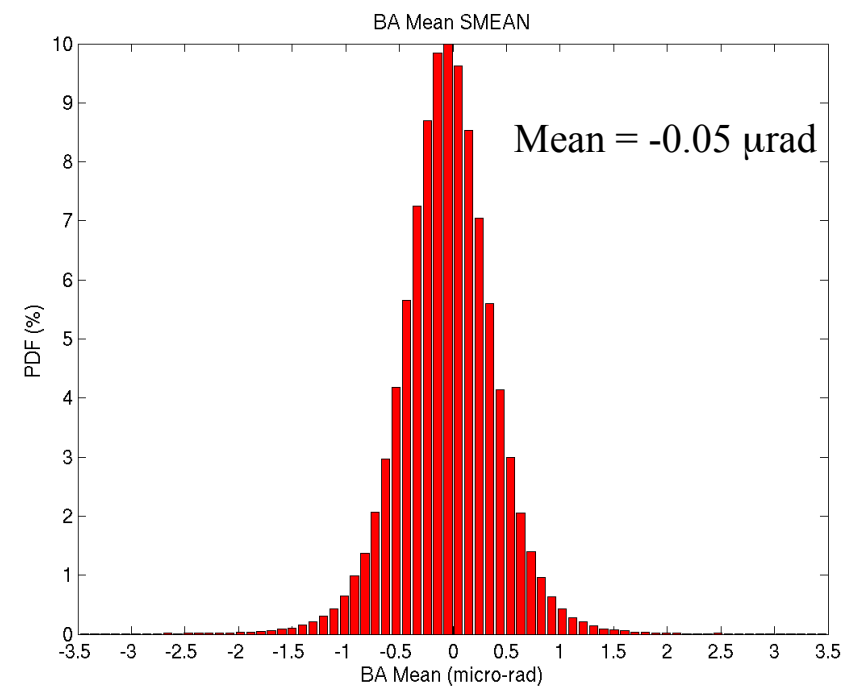

Fig. 17. Distribution of mean bending angle differences (from climatology) between 60 and $80 \mathrm{~km}$ heights for $\sim 308000 \mathrm{~F} 3 \mathrm{C}$ profiles from July-December 2009.

stability of computed bending angles from mission to mission, the difference between the average values of SMEAN for two missions over the same time period provides a good measure of stability as long as the latitudinal and local time sampling of each mission are similar. Figures 17 and 18 show histograms of SMEAN for $~ 308000$ F3C and $\sim 79000$ Metop/GRAS profiles. For calculation of the mean and standard deviation we remove the occultations with $\mid$ SMEAN $\mid<3.5 \mu \mathrm{rad}$ by considering them outliers. For F3C, the mean and standard deviation are -0.05 and $0.46 \mu \mathrm{rad}$, and for Metop/GRAS -0.02 and $0.46 \mu \mathrm{rad}$ respectively. These results suggest that the $\mathrm{F} 3 \mathrm{C}$ bending angles are on average $\sim 0.03 \mu \mathrm{rad}$ smaller than the Metop/GRAS bending angles. One possible cause for the more negative $\mathrm{F} 3 \mathrm{C}$ bending angles is large-scale ionospheric residuals that are expected to be negative (Syndergaard, 2000). These residuals are primarily a function of the square of $\mathrm{F}$ layer peak electron density, and thus, could produce smaller bending angles for F3C than for Metop/GRAS, because F3C fully samples the diurnal cycle and Metop/GRAS samples near 09:30 and 21:30 LST where electron densities are smaller than the maximum $(\sim 14: 00 \mathrm{LST})$. The observed mean difference between the $\mathrm{F} 3 \mathrm{C}$ and Metop/GRAS bending angles of $\sim 0.03 \mu \mathrm{rad}$ is quite small and illustrates the high degree of re-produceability and mission independence of the GPS RO data at high altitudes.

\section{F3C collocated differences}

In an effort to better quantify the bending angle precision of RO instruments, this section examines a set of differences from collocated neutral atmospheric bending angle profiles

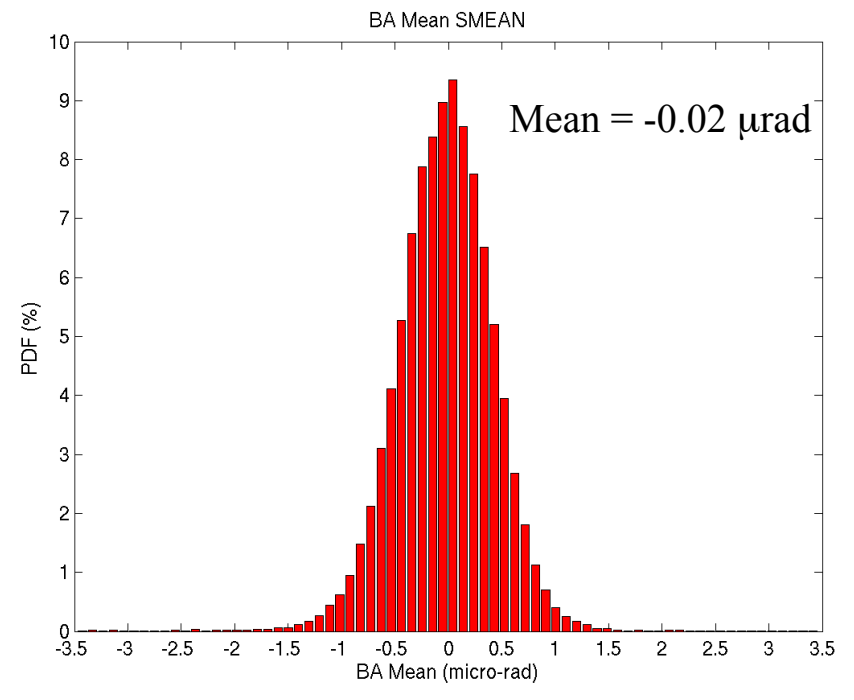

Fig. 18. Distribution of mean bending angle differences (from climatology) between 60 and $80 \mathrm{~km}$ heights for $\sim 79000$ Metop/GRAS profiles from July-December 2009.

between F3C flight model \#3 (F3C/FM3) and F3C flight model \#4 (F3C/FM4). The close proximity of the COSMIC satellites after launch has provided a unique opportunity to estimate the precision of the RO remote sensing technique from closely collocated occultations (Schreiner et al., 2007). It should be noted that these collocated RO soundings allow the precision of the technique to be estimated, but not the accuracy, because any systematic retrieval errors are eliminated when forming the differences. The examination of collocated soundings also provides insight into the stability of RO bending angles from satellite to satellite through analysis of the mean profile differences.

For these statistical comparisons, we use all available pairs of collocated occultations from FM3 and FM4 for DOYs 200-365, 2006, with the horizontal separation of ray TPs between the pairs $<10 \mathrm{~km}$. The collocated bending angle profiles are differenced at common impact heights and the mean and standard deviation of the differences are plotted versus impact height. First, we examine the collocated bending angle differences at large impact heights. Figure 19 shows the statistical results of the bending angle differences between 30 and $60 \mathrm{~km}$ impact height for 4528 pairs of collocated bending angle profiles. The plot shows the mean, standard deviation, standard deviation of the mean, and number of samples as a function of impact height. The average of the mean difference and standard deviation of the mean between 30 and $60 \mathrm{~km}$ impact height are approximately $5 \mathrm{e}-9 \mathrm{rad}$ and $3.2 \mathrm{e}-$ $8 \mathrm{rad}$, respectively. This result demonstrates that GPS RO bending angle profiles derived from different satellites flying the same hardware and firmware are stable at the $3 \mathrm{e}-8 \mathrm{rad}$ level. The average of the standard deviations of the collocated differences between 30 and $60 \mathrm{~km}$ impact height is 


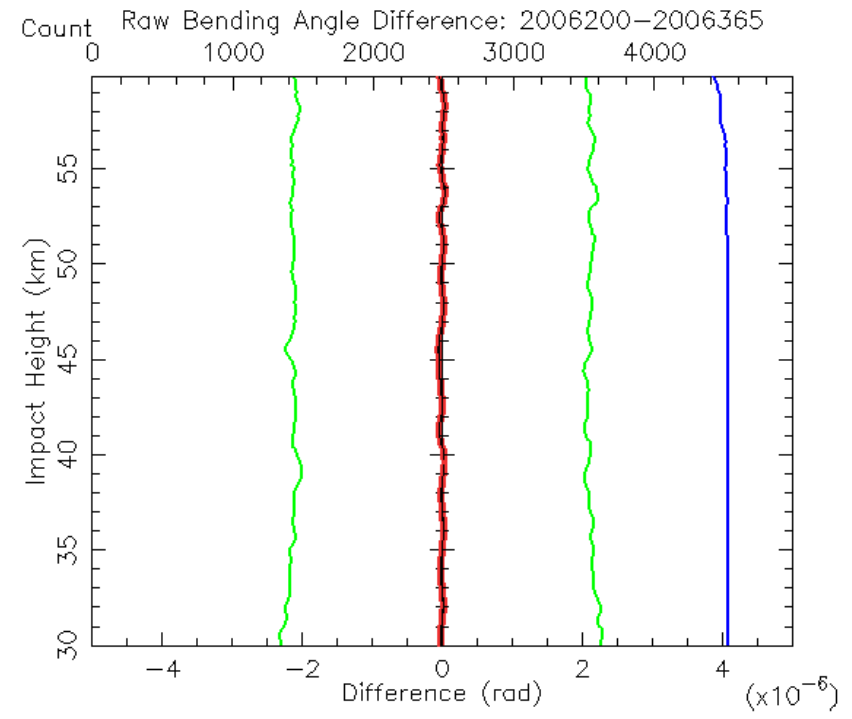

Fig. 19. This plot shows the mean (black), standard deviation (green), standard deviation of the mean (red), and number of samples (blue) as a function of impact height for global differences between FM3 and FM4 bending angles from 2006.200-365.

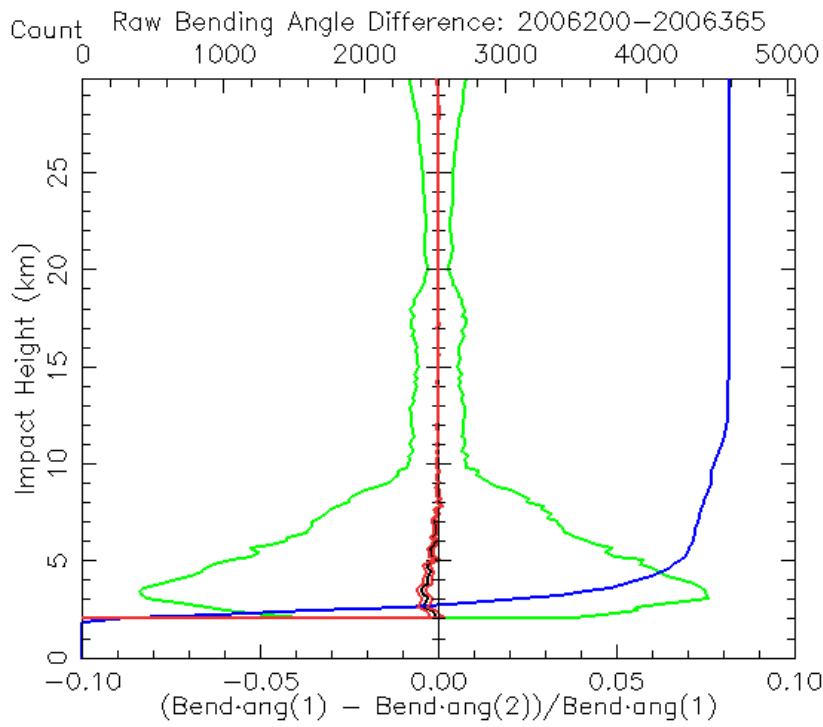

Fig. 20. This plot shows the mean, standard deviation, standard deviation of the mean, and number of samples as a function of impact height for fractional differences between FM3 and FM4 bending angles globally in the lower troposphere from 2006.200-365.

approximately $2.1 \mathrm{e}-6 \mathrm{rad}$, which is consistent with the previous estimate shown in Fig. 15 for individual profiles processed with data from the same side of the F3C satellites, i.e. $\sim 1.44 \mathrm{e}-6 \mathrm{rad}$.

Next, we examine the collocated F3C bending angle differences in the troposphere and lower stratosphere. Figure 20 shows the statistical results of the fractional bending

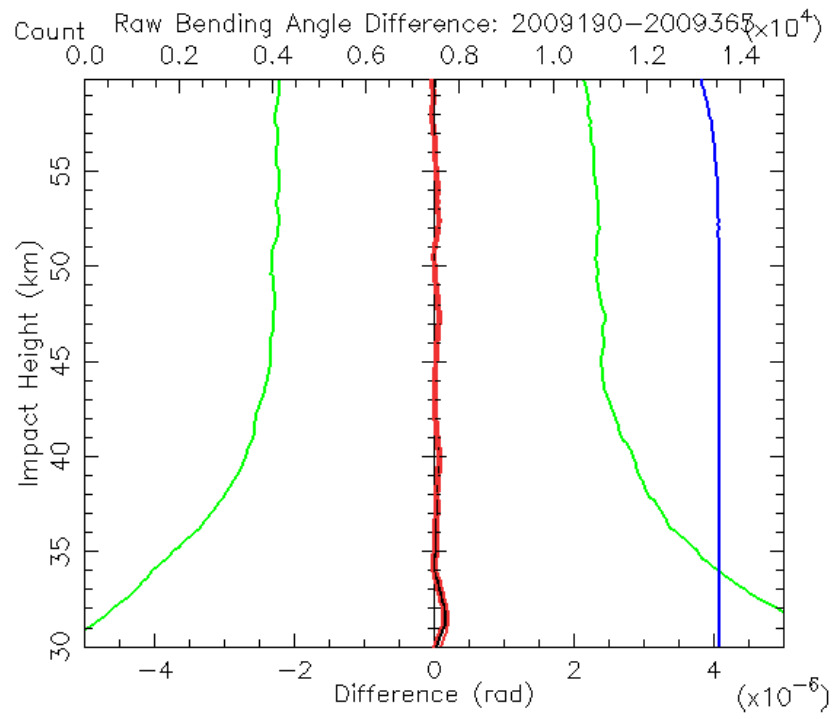

Fig. 21. Statistical comparison of fractional bending angle differences as a function of impact height for global collocated Metop/GRAS and F3C.

angle differences as a function of impact height from the surface to $30 \mathrm{~km}$. Above $10 \mathrm{~km}$ the fractional mean difference is negligible and the standard deviations are less than $1 \%$. The decrease in standard deviation at $20 \mathrm{~km}$ impact height is due to use of this height to constrain the dynamic transition from WO to GO processing. In the lower troposphere, the fractional mean differences between FM3 and FM4 bending angles are statistically significant and as large as $\sim 0.5 \%$, i.e. FM3 bending angles are smaller than FM4. The standard deviation of the differences reaches a maximum of approximately $8 \%$ at $3 \mathrm{~km}$ impact height due to the combined effects of differences in FM3 and FM4 receiver tracking and small-scale $(<10 \mathrm{~km})$ horizontally-inhomogeneous refractivity irregularities. The mean differences can be explained by systematically smaller L1 SNRs (estimated between 60 and $80 \mathrm{~km}$ altitude) observed for all FM3 occultations from 2006.200-365 of $\sim 671 \mathrm{~V} / \mathrm{V}$ as compared to $\sim 737 \mathrm{~V} / \mathrm{V}$ for FM4. This lower FM3 SNR results on average in reduction of the straight-line cutoff depth that has been shown to produce a negative bending angle bias in the LT (Sokolovskiy et al., 2010). The lower SNR for FM3 as compared to FM4, measured at $60-80 \mathrm{~km}$, is caused by such differences in hardware as antenna and pre-amplifier. Additionally, different SNRs in the LT may be caused by instability of clock or differences in real-time navigation solutions that drive the OL model in real time. These reasons limit the satelliteto-satellite re-produceability of $\mathrm{F} 3 \mathrm{C} \mathrm{RO}$ bending angles to about $0.5 \%$ in the LT. 


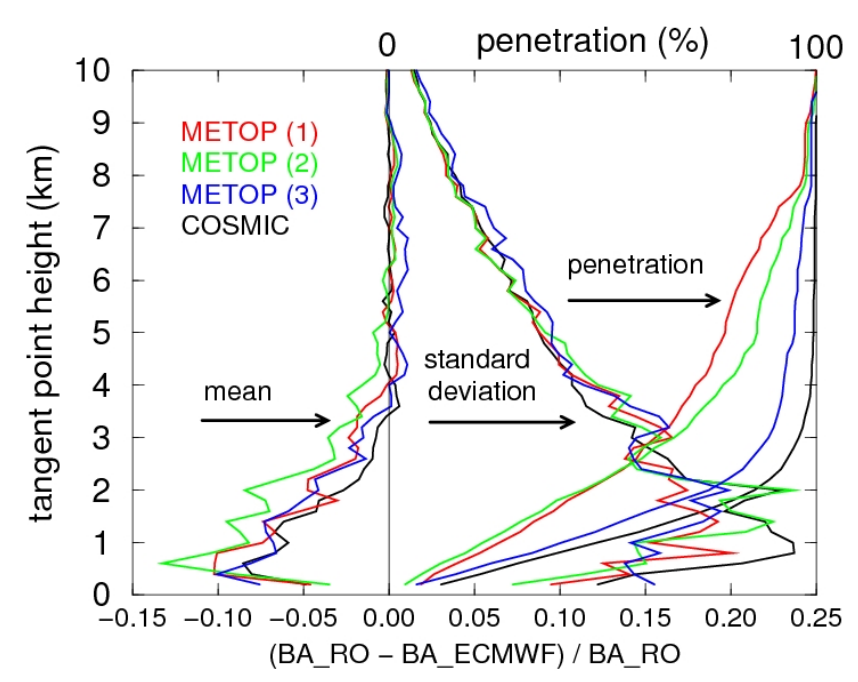

Fig. 22. Statistical comparison of Metop/GRAS and F3C with ECMWF bending angles. Different colors show different Metop/GRAS processing modes (for details see text).

\section{Differences of F3C and Metop/GRAS collocated bending angle profiles}

\subsection{F3C and Metop/GRAS collocated differences at large heights}

This section quantifies the stability between GPS RO instruments with different architectures by examining a set of differences of collocated neutral atmospheric bending angle profiles between Metop/GRAS and F3C at large impact heights. We analyze all pairs of collocated profiles with tangent points within $300 \mathrm{~km}$ and $2 \mathrm{~h}$ of each other from JulyDecember 2009. As shown below, large representativeness errors due to temporal, spatial, and azimuthal angle (of the occultation plane) differences limit the ability of these collocated soundings to quantify the noise level of the RO bending angles. However, their mean differences are still useful for examining stability, i.e. re-produceability, of the bending angle data from the two instruments.

Figure 21 shows the statistical results of the bending angle differences (Metop/GRAS - F3C) between 30 and $60 \mathrm{~km}$ impact height for $\sim 13500$ pairs of collocated bending angle profiles. The average of the mean difference and standard deviation of the mean between 30 and $60 \mathrm{~km}$ impact height are approximately $2 \mathrm{e}-8 \mathrm{rad}$ and $3.2 \mathrm{e}-8 \mathrm{rad}$, respectively. A mean difference of $2 \mathrm{e}-8 \mathrm{rad}$ in bending angle corresponds to approximately $0.07 \mathrm{~mm} \mathrm{~s}^{-1}$ error in velocity. Although this mean is not strongly significant, it still demonstrates that GPS RO bending angle profiles derived from instruments with different architectures are stable at the $3 \mathrm{e}-8 \mathrm{rad}$ level, which illustrates the POD solutions and atmospheric excess phases are consistent within $\sim 0.07 \mathrm{~mm} \mathrm{~s}^{-1}$. The average of the standard deviations of the collocated differences between
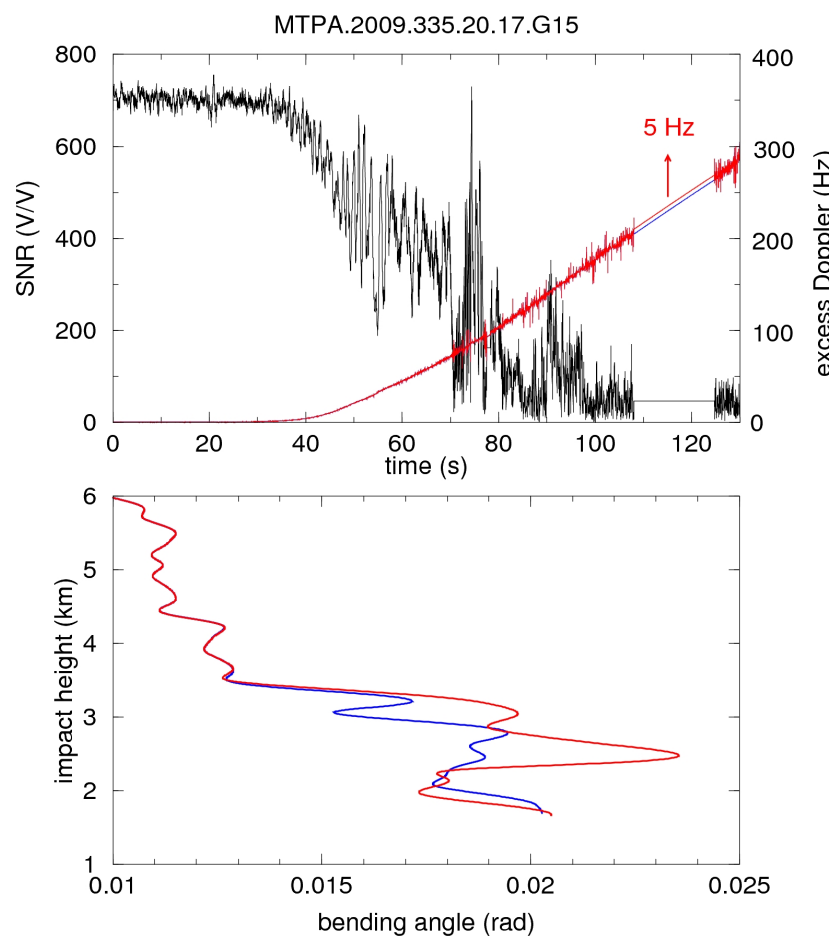

Fig. 23. An example of Metop/GRAS occultation with data gap. Upper panel: SNR and excess Doppler filled with the model inside the gap. Lower panel: retrieved bending angles. Shifting the Doppler model inside the gap by $5 \mathrm{~Hz}$ (upper panel) results in the difference in retrieved bending angles (lower panel).

40 and $60 \mathrm{~km}$ impact height is approximately $2.1 \mathrm{e}-6 \mathrm{rad}$, which is consistent with the previously shown estimates for individual profiles processed with data from the $\mathrm{F} 3 \mathrm{C}$ and Metop/GRAS satellites, i.e. $\sim 1.78 \mathrm{e}-6 \mathrm{rad}$ and $\sim 1.13 \mathrm{e}-6 \mathrm{rad}$, respectively.

\subsection{F3C and Metop/GRAS differences in the troposphere}

In this section we examine Metop/GRAS and F3C bending angle differences in the troposphere. This is a more complicated task due to increased structural uncertainty due to the presence of gaps in Metop/GRAS data and different F3C and Metop/GRAS tracking depths. While 50\% of $\mathrm{F} 3 \mathrm{C}$ occultations are tracked down to $-170 \mathrm{~km}$ of the height of straight line GPS-LEO (Sokolovskiy et al., 2010), $50 \%$ of Metop/GRAS occultations are tracked down to about $-100 \mathrm{~km}$ (Bonnedal et al., 2010a). For comparison, we process Metop/GRAS data in three modes: (1) down to first gap; (2) down to the point where the total length of included gaps is less than $4 \mathrm{~s}$ and the length of any one gap is less than $2 \mathrm{~s}$; (3) processing all signals down to the bottom of an occultation including all gaps. In the modes 1 and 2 we apply the additional criterion for truncation of RO signals based on deviation of excess Doppler from the reference model (Kuo 


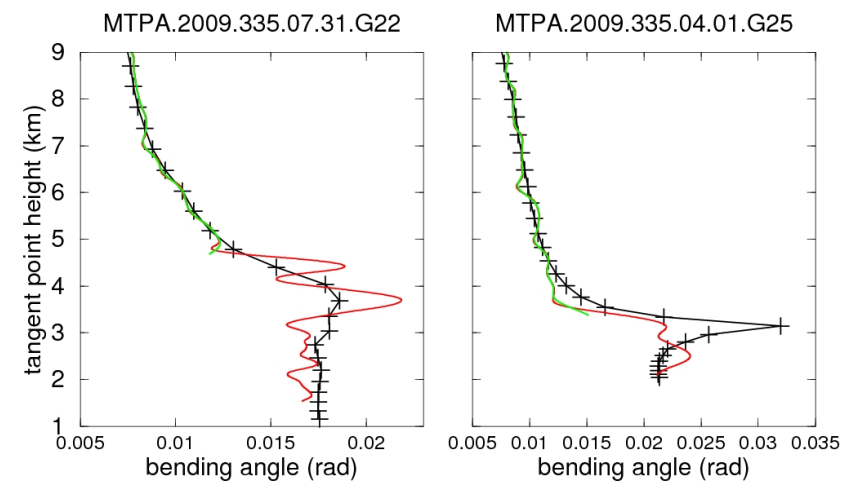

Fig. 24. Two examples of Metop/GRAS bending angles retrieved by different processing modes: mode 1 - down to first gap (green); mode 2 - including small gaps (red). Black line shows ECMWF bending angles for comparison.

et al., 2004), because the PLL tracking in Metop/GRAS is applied to lower straight-line heights than in F3C and thus may have higher probability of tracking errors. In option 3 this truncation is disabled since the purpose of this option is processing of all available data for comparison. F3C bending angles are retrieved with truncation of RO signals based on SNR, as discussed in (Sokolovskiy et al., 2010). Applying this truncation approach for Metop/GRAS is not possible due to data gaps. Figure 22 shows statistical comparison of F3C and the Metop/GRAS bending angles to ECMWF for tropics $(-30 \mathrm{deg}<$ lat $<30 \mathrm{deg})$. The most significant differences between different processings are in penetration, but there are also differences in standard and mean deviations. F3C shows the deepest penetration and smallest mean deviation, but the largest standard deviation at $1 \mathrm{~km}$. The closest to F3C is Metop/GRAS mode 3 (processing all signals), but the proximity of these statistics does not justify the use of this processing mode because of gaps in Metop/GRAS data. Figure 23 shows an example of a Metop/GRAS occultation with the gap filled with the climatology-based Doppler model and the retrieved bending angle. It is seen that shifting of the Doppler model by $5 \mathrm{~Hz}$ results in significant difference in the retrieved bending angle. Thus processing of all Metop/GRAS RO signals including all gaps makes the inversion results in the LT model-dependent. The most justified processing mode (providing minimum structural uncertainty) is mode 1 (processing without gaps) though it results in the poorest penetration. The processing mode 2 that includes only small gaps slightly improves penetration at the expense of increase of the mean difference. It is difficult to explain this effect. Analysis of individual occultations shows that in some cases filling small data gaps improves penetration by providing reasonably looking retrievals as shown in left panel of Fig. 24. In other cases, especially in the presence of sharp top of the boundary layer, including small data gaps results in significant negative bias as shown in right panel of Fig. 24 .

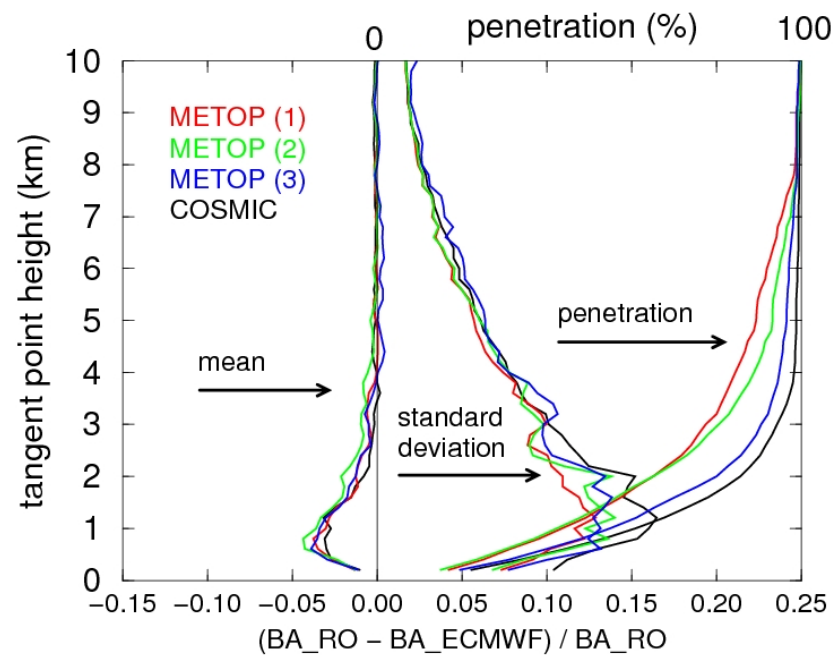

Fig. 25. Same as Fig. 22 but for all latitudes.

It is possible that this bias is responsible for the increase of the mean difference of processing mode 2 compared to mode 1 as this is seen in Fig. 22. Figure 25 shows the same as Fig. 22 but for all latitudes. The differences between different processings are less pronounced in global than in tropical statistics but qualitatively are similar. The current processing mode at CDAAC for Metop/GRAS data is option 2, but this will be reconsidered, especially in view of results presented here and proposed updates for Metop/GRAS firmware (Bonnedal et al., 2010b).

\section{Conclusions}

This study has attempted to quantify the precision (degree of reproducibility) of GPS RO bending angles in terms of random and systematic differences for different satellites and instruments. We used six months (June-December 2009) of data from the F3C and Metop/GRAS missions that were processed by the UCAR CDAAC to analyze bending angle profile differences from climatology and differences between collocated profiles. Between 60 and $80 \mathrm{~km}$ the standard deviation of the Metop/GRAS bending angle differences from climatology are smaller $(1.13 \mu \mathrm{rad})$ than those from F3C $(1.78 \mu \mathrm{rad})$, because the Metop/GRAS data use zero-difference processing that does not include phase noise from the reference satellite observations. The F3C standard deviation reduces significantly to $1.44 \mu \mathrm{rad}$ when singledifference processing uses GPS satellites on the same side of the spacecraft. The reason for smaller noise of sameside occultations is not understood and is under investigation. The F3C mean bending angles differences relative to climatology are smaller than those for Metop/GRAS by approximately $0.03 \mu \mathrm{rad}$ and may be due to large-scale ionospheric residuals that are expected to be negative and should have more impact on $\mathrm{F} 3 \mathrm{C}$ since it samples the full diurnal 
cycle. This difference is quite small and illustrates the high degree of re-produceability and mission independence of the GPS RO data at high altitudes. In the LT, especially in the tropics, insufficient straight-line tracking depth limits the reconstruction of the true bending angle profile. For example, collocated bending angles between two F3C satellites from early in the mission differ on average by up to $0.5 \%$ near the surface due to systematically lower signal-to-noise ratio for one of the satellites that affects its cutoff depth. The difference between F3C and Metop/GRAS bending angles in the lower troposphere depends on the Metop/GRAS processing mode. On average, Metop/GRAS bending angles are negatively biased compared to $\mathrm{F} 3 \mathrm{C}$ with a maximum of several percents in tropical regions. This bias is related to a higher observed RO signal cutoff height for Metop/GRAS that is due to the receiver being configured to track signals down to an insufficient height. The differences between different processing modes are related to data gaps. This increases the structural uncertainty of Metop/GRAS inversions compared to F3C. This uncertainty may be reduced in the future with changes of the Metop/GRAS receiver firmware (Bonnedal et al., 2010b). The results of processing of Metop/GRAS rawsampled data with different down-samplings suggest the use of $100 \mathrm{~Hz}$ sampling in the $\mathrm{LT}$ in future $\mathrm{RO}$ receivers.

Acknowledgements. This material is based upon work supported by the National Science Foundation under Cooperative Agreement No. AGS-0918398/CSA No. AGS-0939962 and work supported by the EUMETSAT under Award No. EUM/CO/09/4600000677/AVE. The authors are grateful to Jay Fein for support of the CDAAC, to the JPL receiver team for implementing and debugging the COSMIC receiver firmware, and to EUMETSAT for assistance in decoding the GRAS data, and GRAS precise orbits used for comparison.

Edited by: A. K. Steiner

\section{References}

Anthes, R. A., Bernhardt, P. A., Chen, Y., Cucurull, L., Dymond, K. F., Ector, D.,Healy, S. B., Ho, S.-P., Hunt, D. C., Kuo, Y.-H., Liu, H., Manning, K., McCormick, C., Meehan, T. K., Randel, W. J., Rocken, C., Schreiner, W. S., Sokolovskiy, S. V., Syndergaard, S., Thompson, D. C., Trenberth, K. E., Wee, T.-K., Yen, N. L., and Zeng, Z.: The COSMIC/FORMOSAT-3 mission: early results, B. Am. Meteorol. Soc. (BAMS), 89, 313-333, 2008.

Beyerle, G., Schmidt, T., Michalak, G., Heise, S., Wickert, J., and Reigber, C.: GPS radio occultation with GRACE: Atmospheric profiling utilizing the zero difference technique, Geophys. Res. Lett., 32, L13806, doi:10.1029/2005GL023109, 2005.

Bonnedal, M., Christensen, J., Carlstroem, A., and Berg, A.: Metop-GRAS in-orbit instrument performance, GPS Solut., 14, 109-120, doi:10.1007/s10291-009-0142-3, 2010a.

Bonnedal, M., Carlstroem, A., Christensen, J., Lindgren, T., GRAS on Metop: Instrument characteristics and performance evaluation, The International Workshop on Probing the Atmospheric and Climate, OPAC 4, Graz, Austria, 6-10 September 2010, $2010 b$.

Cucurull, L., Derber, J. C., Treadon, R., and Purser, R. J.: Preliminary impact studies using Global Positioning System radio occultation profiles at NCEP, Mon. Weather Rev., 136, 1865-1877, 2008.

Dach, R., Hugentobler, U., Fridez, P., and Meindl, M. (Eds.): User manual of the Bernese GPS Software Version 5.0, Astronomical Institute, University of Berne, Switzerland, January, 2007.

Gorbunov, M. E.: Canonical transform method for processing radio occultation data in the lower troposphere, Radio Sci., 37, 1076, doi:10.1029/2000RS002592, 2002.

Gorbunov, M. E. and Lauritsen, K. B.: Analysis of wave fields by Fourier integral operators and their application for radio occultations, Radio Sci., 39, RS4010, doi:10.1029/2003RS002971, 2004.

Hardy, K. R., Hajj, G., Kursinski, R., and Ibanez-Meier, R.: Accuracies of Atmospheric Profiles Obtained from GPS Occultations, ION Satellite Division 6th International Technical Meeting, GPS-93, Salt Lake City, UT, 22-24 September, 1993.

Hajj, G. A., Kursinski, E. R., Romans, L. J., Bertiger, W. I., and Leroy, S. S.: A technical description of atmospheric sounding by GPS occultation, J. Atmos. Sol.-Terr. Phys., 64, 451-469, 2002.

Hajj, G. A., Ao, C. O., Iijima, B. A., Kuang, D., Kursinski, E. R., Mannucci, A. J., Meehan, T. K., Romans, L. J., de la Torre Juarez, M., and Yunck, T. P.: CHAMP and SAC-C atmospheric occultation results and intercomparisons, J. Geophys. Res., 109, D06109, doi:10.1029/2003JD003909, 2004.

Healy, S.: Operational assimilation of GPS radio occultation measurements at ECMWF, ECMWF Newsletter, 111, Spring, 2007.

Ho, S.-P., Kirchengast, G., Leroy, S., Wickert, J., Mannucci, A. J., Steiner, A., Hunt, D., Schreiner, W., Sokolovskiy, S., Ao, C., Borsche, M., von Engeln, A., Foelsche, U., Heise, S., Iijima, B., Kuo, Y.-H., Kursinski, R., Pirscher, B., Ringer, M., Rocken, C., and Schmidt, T.: Estimating the uncertainty of using GPS radio occultation data for climate monitoring: Intercomparison of CHAMP refractivity climate records from 2002 to 2006 from different data centers, J. Geophys. Res., 114, D23107, doi:10.1029/2009JD011969. 2009a.

Ho, S.-P., Goldberg, M., Kuo, Y.-H., Zou, C.-Z., and Schreiner, W.: Calibration of temperature in the lower stratosphere from microwave measurements using COSMIC radio occultation: preliminary results, Terr. Atmos. Ocean. Sci., 20, 87-100, doi:10.3319/TAO.2007.12.06.01(F3C), 2009b.

Hwang, C., Tseng, T. P., Ling, T., Svehla, D., and Schreiner, B.: Precise orbit determination for the FORMOSAT3/COSMIC satellite mission using GPS, J. Geod., 83, 477-489, doi:10.1007/s00190-008-0256-3, 2008.

Jensen, A. S., Lohmann, M. S., Benzon, H., and Nielsen, A. S.: Full spectrum inversion of radio occultation signals, Radio Sci., 38, 1040, doi:10.1029/2002RS002763, 2003.

Jensen, A. S., Lohmann, M. S., Nielsen, A. S., and Benzon, H.: Geo- metric optics phase matching of radio occultation signals, Radio Sci., 39, RS3009, doi:10.1029/2003RS002899, 2004.

Kirchengast, G., Hafner, J., and Poetzi, W.: The CIRA86aQ_UoG model: An extension of the CIRA-86 monthly tables including humidity tables and a Fortran95global moist air climatology model, IMG/UoG Tech. Rep. 8, Eur. Space Agency, Paris, France, 1999. 
Komjathy, A., Wilson, B., Pi, X., Akopian, V., Dumett, M., Iijima, B., Verkhoglyadova, O., and Mannucci, A. J.: JPL/USC GAIM: On the impact of using COSMIC and ground-based GPS measurements to estimate ionospheric parameters, J. Geophys. Res., 115, A02307, doi:10.1029/2009JA014420, 2010.

Kuo, Y.-H., Wee, T.-K., Sokolovskiy, S., Rocken, C., Schreiner, W., Hunt, D., and Anthes, R. A.: Inversion and error estimation of GPS radio occultation data, J. Met. Soc. Japan, 82, 507-531, 2004.

Kursinski, E. R., Hajj, G. A., Schofield, J. T., Linfield, R. P., and Hardy, K. R.: Observing Earth's atmosphere with radio occultation measurements using the Global Positioning System, JGR, 102, 23429-23465, 1997.

Leroy, S. S.: The measurement of geopotential heights by GPS radio occultation, J. Geophys. Res., 102, 6971-6986, 1997.

Melbourne, W., Davis, E., Duncan, C., Hajj, G., Hardy, K., Kursinski, E., Meehan, T., Young, L., and Yunck, T.: The application of space borne GPS to atmospheric limb sounding and global change monitoring, JPL Publ., 94-18, 147 pp., 1994.

Montenbruck, O., Andres, Y., Bock, H., van Helleputte, T., van den Ijssel, J., Loiselet, M., Marquardt, C., Silvestrin, P., Visser, P., and Yoon, Y.: Tracking and orbit determination performance of the GRAS instrument on MetOp-A, GPS Solutions, 12, 289-299, doi:10.1007/s10291-008-0091-2, 2008.

Ohring, G. (Ed.): Achieving Satellite Instrument Calibration for Climate Change, National Oceanographic and Atmospheric Administration, 144 pp., 2007.

Rocken, C., Anthes, R., Exner, M., Hunt, D., Sokolovskiy, S., Ware, R., Gorbunov, M., Schreiner, W., Feng, D., Herman, B., Kuo, Y.H., and Zou, X.: Analysis and validation of GPS/MET data in the neutral atmosphere, J. Geophys. Res., 102, 29849-29860, 1997.

Svehla, D. and Rothacher, M.: Kinematic and reduced-dynamic precise orbit determination of low earth orbiters, Adv. Geosci., 1, 47-56, 2003, http://www.adv-geosci.net/1/47/2003/.

Schreiner, W., Rocken, C., Sokolovskiy, S., Syndergaard, S., and Hunt, D.: Estimates of the precision of GPS radio occultations from the COSMIC/FORMOSAT-3 mission, Geophys. Res. Lett., 34, L04808, doi:10.1029/2006GL027557, 2007.

Schreiner, W., Rocken, C., Sokolovskiy, S., and Hunt, D.: Quality Assessment of COSMIC/FORMOSAT-3 GPS Radio Occultation Data Derived from Single- and Double-Difference Atmospheric Excess Phase Processing, GPS Solut., 14, 13-22, doi:10.1007/s10291-009-0132-5, 2009.

Schreiner, W., Sokolovskiy, S., Rocken, C., Hunt, D., and Kuo, Y.H.: GPS RO processing from raw phase and amplitude to bending angle, The International Workshop on Probing the Atmospheric and Climate, OPAC 4, Graz, Austria, 6-10 September, 2010.

Sokolovskiy S.: Tracking tropospheric radio occultation signals from low Earth orbit, Radio Sci., 36, 483-498, 2001.
Sokolovskiy, S.: Open loop tracking and inverting GPS radio occultation signals, in: Occultations for Probing Atmosphere and Climate, edited by: Kirchengast, G., Foelsche, U., and Steiner, A., Springer-Verlag, 37-51, 2004.

Sokolovskiy, S., Rocken, C., Schreiner, W., Hunt, D., and Johnson, J.: Postprocessing of L1 GPS radio occultation signals recorded in open-loop mode, Radio Sci. 44, RS2002, doi:10.1029/2008RS003907, 2009a.

Sokolovskiy, S., Schreiner, W., Rocken, C., and Hunt, D.: Optimal noise filtering for the ionospheric calibration of GPS radio occultation signals, J. Atmos. Oceanic Technol., 26, 1398-1403, doi:10.1175/2009JTECHA1192.1, 2009b.

Sokolovskiy, S., Rocken, C., Schreiner, W., and Hunt, D.: On the uncertainty of radio occultation inversions in the lower troposphere, J. Geophys. Res., 115, D22111, doi:10.1029/2010JD014058, 2010.

Staten, P. W. and Reichler, T.: Apparent precision of GPS radio occultation temperatures, Geophys. Res. Lett., 36, L24806, doi:10.1029/2009GL041046, 2009.

Steiner, A. K., Kirchengast, G., Lackner, B. C., Pirscher, B., Borsche, M., and Foelsche, U.: Atmospheric temperature change detection with GPS radio occultation 1995 to 2008, Geophys. Res. Lett., 36, L18702, doi:10.1029/2009GL039777, 2009.

Syndergaard, S.: On the ionosphere calibration in GPS radio occultation measurements, Radio Sci., 35, 865-883, 2000.

von Engeln, A., Andres, Y., Marquardt, C., and Sancho, F.: GRAS Radio Occultation on-board of Metop, Adv. Space Res., 47, 336347, doi:10.1016/j.asr.2010.07.028, 2011.

Vorob'ev, V. V. and Krasil'nikova, T. G.: Estimation of the accuracy of the atmospheric refractive index recovery from Doppler shift measurements at frequencies used in the NAVSTAR system, Izv. Russ. Acad. Sci., Atmos. Oceanic. Phys., Engl. Transl., 29, 602609, 1994.

Ware, R., Exner, M., Feng, D., Gorbunov, M., Hardy, K., Herman, B., Kuo, Y., Meehan, T., Melbourne, W., Rocken, C., Schreiner, W., Sokolovskiy, S., Solheim, F., Zou, X., Anthes, R., Businger, S., and Trenberth, K.: GPS Sounding of the Atmosphere from Low Earth Orbit: Preliminary Results, B. Am. Meteorol. Soc., 77, 19-40, doi:10.1175/15200477(1996)077;0019:GSOTAF; 2.0.CO;2, 1996.

Wickert, J., Beyerle, G., Hajj, G. A., Schwieger, V., and Reigber, C.: GPS radio occultation with CHAMP: Atmospheric profiling utilizing the space-based single difference technique, Geophys. Res. Lett., 29, 1187, doi:10.1029/2001GL013982, 2002.

Yunck, T. P. and Lindal, G. F.: The Role of GPS in Precise Earth Observation, Proc. IEEE Position Location \& Navigation Symposium, Orlando, FL, 1988. 